\title{
The Gastrointestinal Manifestations of Systemic Lupus Erythematosus: A Survey of the Literature
}

\author{
Steffan W. Schulz and Chris T. Derk* \\ Division of Rheumatology, Thomas Jefferson University, Philadelphia, PA 19107, USA
}

\begin{abstract}
Systemic Lupus Erythematosus (SLE) is an autoimmune disease associated with auto-antibody production and resulting widespread inflammation that has potential to affect and damage many organ systems. Gastrointestinal manifestations of SLE are well documented in the literature but the exact extent and frequency of their presence is likely grossly underestimated. Patients present with vague complaints such as abdominal pain and nausea with non-specific physical exam findings and inconclusive diagnostic tests and serologic analysis. Recent research has helped to better clarify these manifestations of SLE and has demonstrated distinct involvement of almost every portion of the GI tract. This article is based upon an exhaustive review of the literature from 1976 to present date and summarizes the major advances in the identification and differentiation of gastrointestinal incarnations related to systemic lupus erythematosus. The review also encompasses theories of etiology of the various manifestations, summarizes accepted and experimental treatment regimens, and highlights the differential diagnosis of each presented topic, including disorders of the oropharynx, esophagus, stomach, small and large intestine, liver and gallbladder and beyond.
\end{abstract}

Key Words: Systemic lupus erythematosus, gastrointestinal, pancreas, liver, intestines, stomach, esophagus.

\section{INTRODUCTION}

Systemic Lupus Erythematosus (SLE) is an autoimmune disease associated with systemic inflammation affecting multiple organ systems and ultimately presenting in patients as a spectrum of disease with varied manifestations and multiple sub-types. SLE shows a $90 \%$ female predominance typically affecting woman in their childbearing years, although disease in males, children and those over the age of 50 is not uncommon. The approach to diagnosing SLE has been refined several times by the American College of Rheumatology [1-3] and defines SLE upon the presence of 4 out of 11 defined criteria that include commonly occurring manifestations such as arthritis, various forms of cutaneous lesions and renal, pulmonary, cardiac or central nervous system abnormalities. Additional criteria include the serologic presence of auto-antibodies. SLE is strongly associated with the presence of anti-nuclear antibodies (ANA), anti-phospholipid antibodies and several sub-types of ANA antibodies with specific nuclear targets such as anti-double stranded DNA and anti-snRNP protein (anti-smith) antibodies.

The pathogensis of SLE centers upon the uncontrolled activation of the immune system with widespread inflammation manifested by constitutional symptoms of fever, fatigue, weight loss and often serologic evidence of an elevated sedimentation rate and activation of the complement cascade with resulting depletion. Effects of the unchecked inflammatory response can be system wide or organ specific and can

*Address correspondence to this author at the Thomas Jefferson University, Division of Rheumatology, 613 Curtis Bldg, 1015 Walnut Street, Philadelphia, PA 19107, USA; Tel: 215-955-9723; Fax: 215-923-7885;

E-mail: Chris.Derk@jefferson.edu include generalized inflammatory cell infiltration, complement and immune complex deposition and large and small sized- vascular dysfunction and resulting tissue damage. General theories explaining the etiology of SLE focus on the production of auto-antibodies that target the cell nucleus. The process likely results from a combination of circumstances that includes genetic predisposition, environmental exposure along with abnormal and uncontrolled innate and humoral immune responses.

SLE has a varied presentation and can affect many organ systems at different times over the course of the disease and can make the diagnosis of lupus a challenge for clinicians. Some manifestations, such as musculo-skeletal and cutaneous signs, are common and unique to SLE; organ specific inflammation (renal, pulmonary or gastro-intestinal) can mimic other conditions, causing delay in disease recognition and treatment that attributes to the significant morbidity and mortality of SLE. The focus of this review will be to analyze the effects of SLE on the gastrointestinal tract, highlighting the many presentations from the mouth to the anus that will cumulatively affect $25-40 \%$ of all SLE patients. Focus will be given to distinguish SLE GI manifestations from both other disease processes and from side effects of medications used to treat the primary disease to help the clinician recognize the presence of SLE and offer the patient the best opportunity to treat and alleviate their effects leading to a reduced disease related morbidity and mortality.

The review was performed through analysis of over 316 publications that were obtained through a comprehensive PubMed search for relevant articles from 1976 to the present. Articles were selected based on their relevance to the subject 
matter based upon their subject matter, content and the clinical relevance determined by the authors.

\section{DISCUSSION}

\section{Oral Cavity}

The presence of oral ulcers in systemic lupus erythematosus (SLE) patients was first described over a hundred years ago. As one of the current diagnostic criteria for SLE [1, 2], oral cavity lesions continue to retain a vast clinical significance for rheumatologists. Various surveys over the years have estimated a wide range of prevalence but studies of larger populations tend to estimate $19-30 \%$ of SLE patients suffer from disease related oral manifestations [4-9].

Oral cavity lesions are now classified as one of several sub-types, a distinction made only recently among investigators. Three variants exist: discoid, erythematous or ulcerlike. Discoid lesions are noted for their red center with telangiectasias and light-colored borders; erythematous lesions look like flat macules also with telangiectasias and lack the distinct border seen in the discoid type; ulcerative lesions occur in crops and are shallow with an average diameter of $1-2 \mathrm{~mm}[8,10]$. Patients afflicted with oral lesions may complain of pain but the majority of those directly associated with SLE are usually painless; Urman's study of 182 patients showed $82 \%$ of those with lesions had no symptoms [6]. While some studies have found higher frequencies of painful ulcers [11], Wallace reports these ulcers may be from origins other than SLE (apthous stomatitis, infections, drugs, etc) [12]. Most investigations do not typically differentiate among the sub-types in their reporting of painful lesions but differences do exist. Discoid and ulcerative lesions are more commonly painful and erythematous lesions are not [8]. These lesions are typically located on the hard palate (up to $89 \%$ of lesions) [6] although the buccal mucosa, vermilion border and pharynx may also be involved. Despite the commonality of these presentations, the oral lesions of SLE can be quite varied and differences of size, location, color and quality of pain are often seen; lesions of different varieties can also overlap. Because of this variety, careful oral examinations should be performed in all patients evaluated for SLE.

It can be difficult to differentiate the oral lesions of SLE from other diseases of the oral cavity such as lichen planus and oral leukoplakia [10]. Sanchez showed oral SLE/ discoid lesions have T-cells predominately in the lamina propria, submucosa and epithelium as well as a high proportion of macrophages but still noted difficulty in differentiating the lesions from other chronic inflammatory disorders [13]. Karjalainen followed this article noting several histologic differences unique to SLE oral lesions including PAS positive deposits in the subepithelium, PAS positive vessel wall thickening with perivascular inflammatory cell infiltrate and keratinocyte vacuolization [14].

Oral lesions and ulcers do tend to appear in more patients with severe disease and their presence have been associated with overall activity of a patient's SLE and organ related processes [6]. Schiodt suggested that discoid oral lesions could be the first presentation of discoid disease or SLE and felt their presence could be a predictor of future systemic disease [15]. Other authors and studies have not supported this conclusion [8] and note that oral lesions can be seen in isolation from any other disease activity [11]. There has been the suggestion that anti-Smith antibodies hold an association with oral ulcers [5] but thus far other studies have not found a firm connection between the lesions and the presence of specific antibodies or complement levels. Some oral lesions could easily be associated with the presence of a secondary sjogrens syndrome and the clinician must be careful to rule out sicca symptoms in evaluating any oral lesions. Besides the association of oral ulcers in patients with the overlap syndrome of myositis and SLE as noted by Dayal and Isenberg [16], no other firm connections between oral lesions and a specific disease process have been found.

A wide range of treatment options exist for oral manifestations. Topical agents such as oral lidocaine and anesthetic mouthwash preparations are useful in managing the pain of the discoid and ulcerative lesions. To date, there is a void of studies available to demonstrate the efficacy of systemic agents in the treatment of oral lesions. In the international survey by Vitali, hydroxychloroquine was the most preferred drug for oral lesions with $85 \%$ of respondents reporting its use; azathioprine $(59 \%)$ and dapsone $(41 \%)$ were also frequently used [4]. More potent medications such as thalidomide, oral or IV high-dose corticosteroids and cyclosporine are usually reserved for severe and refractory cases. In most studies, it has been noted that treatment of the systemic illness as a whole will lead to the subsequent resolution of any oral signs and symptoms.

Oral manifestations in SLE are a common phenomenon and can often be accurately used as a diagnostic tool or a marker of disease activity and flare. Care should be taken to distinguish their presence from either lesions such as lichen planus [12] or infectious causes that are often associated with SLE [17] and often a result of immuno-suppressive therapies.

\section{Esophagus}

Hallegua noted a frequency of dysphagia ranging from 1$6 \%$ [12] in SLE patients, a figure that was supported in a later review by Sultan who estimated the range at $1-10 \%$ [8]. A major cause of dysphagia is due to impaired esophageal motility. It was found that $8 / 14$ patients with dyspagia had some degree of motility problem although only 3 were labeled as severe [18]. Castrucci et al. studied 18 SLE patients with manometry and noted some form of hypokinetic esophageal dysfunction in $72 \%$ of those surveyed [19]. He went on to suggest that such dysfunction may be related to a vasculitic process in either the smooth muscles or the nerves of the Auerbach plexus. An earlier study looked at 50 randomly selected SLE patients with manometry and noted 16 had some findings of dysmotility [20]. Of these, the majority had dysfunction mostly in the upper $1 / 3$ of the esophagus. A series of 26 autopies performed in children affected by SLE with no history of dysphagia found $2 / 26$ had esophageal skeletal muscle fiber atrophy [21].

A second possible explanation for the dysphagia seen in SLE patients can be related to gastroesophageal reflux disease (GERD). Symptomatic GERD has been estimated to occur in a range of $11-50 \%$ of SLE patients [8]. Castrucci noted more than $50 \%$ of the patients he surveyed had GERD. The combination of potent medicines used in SLE, including 
chronic NSAID usage, along with traditional risk factors seen in the general population, is usually presumed to be the cause. Studies investigating the role of the lower esophageal sphincter (LES) have not noted any major alteration in its function. A study by Lapadula of 150 patients using manometry noted that unlike scleroderma and other connective tissue diseases, the LES appears to function with near normality in SLE [22].

Physicians should be careful to investigate the association of dysphagia in SLE patients with a possible diagnosis of secondary sjogrens syndrome, as sicca symptoms can also mimic symptoms of esophageal dysfunction. There has been a long presumed association between the presence of secondary Raynaud's phenomenon and dysphagia symptoms. A study by Gutierrez noted the connection when comparing swallowing function in patients with SLE and Mixed Connective Tissue Disease (MCTD) and found dysfunction of peristalsis was highly associated with symptoms of Raynaud's [18]. More recently the connection has been questioned as the Lapadula study noted a much poorer association between the two phenomena [22]. Esophageal spasm can cause symptoms of intense dysphagia with chest pain and has been described in some case reports [23]. Rare case reports suggest a potential association of epidermolysis bullosa acquisita with dysphagia [24]. Another single case report presented by $\mathrm{Yu}$ documents the presence of dysphagia in a patient with a focal CNS lesion in the vagus nerve nuclei and resulting vagal nerve dysfunction requiring temporary gastric feeding tube [25].

Most patients will be evaluated initially with a barium swallow but manometry remains the prime means of effectively diagnosing peristaltic dysfunction or abnormal sphincter pressures. Concerns of ulceration or documentation and investigation of reflux disease requires an upper endoscopy with the typical testing for H-pylori presence. Biopsy can be done for definitive diagnosis if vasculitis is suspected. Effective treatment of dysphagia is fairly similar despite the potential difference in the origin of symptoms. Non-pharmacologic attempts to improve dysphagia symptoms include more frequent and smaller meals, smoking cessation and avoiding recumbency immediately after meals. Additional moderation of the consumption of alcohol, fatty foods, chocolate, peppermint, caffeine and carbonated beverages has also been long suggested with proven benefit [26]. H-2 Blockers such as ranitidine and PPIs such as omeprazole are traditionally considered effective starting points for therapy. More recently the choice for monotherapy has centered upon using PPIs for GERD given results of studies such as the ASTRONAUT trial proving the superiority of omeprazole over ranitidine for acid suppression [27]. Esophageal spasm can be treated with combinations of nitrates and calcium channel blockers. Studies looking at the specific treatment of dysphagia in the SLE patient are unfortunately lacking.

Esophageal dysfunction in SLE can be the result of localized inflammation resulting in vasculitis or muscle fiber atrophy but is also commonly associated with secondary causes. Careful history, radiographic analysis and possibly upper endoscopy may be needed to distinguish between the direct effect of SLE and medication side effects, sicca symptoms and damage from chronic GERD.

\section{Stomach}

The most common gastric pathology manifested in SLE remains gastritis and peptic ulcer disease. Hallegua found the incidence of peptic ulcer disease to be in the range of $4-21 \%$ [12], but in Sultan's review it is noted that no studies addressing the frequency of ulcers specifically in SLE have ever been done and notes the scarce data that exists is from an era pre-dating the use of PPIs [8]. However, a strong link between SLE and gastritis and ulceration remains established as patient use of anti-inflammatory drugs is obviously common in SLE and has well been documented as causing the development of peptic ulcer disease. NSAIDs have long been associated with the development of Peptic Ulcer Disease (PUD) from their inhibition of prostaglandin synthesis. Myths about certain NSAIDs being less dangerous than others are not well founded. A study by Griffin showed there are no "safe NSAIDs" and that all are dose dependent in their risk of mucosal compromise. More-so, the myth of the stomach adapting to their use over time was also dissuaded by this study [28]. NSAIDs by themselves have been shown to pose a greater risk to the integrity of the stomach lining than the isolated use of steroids, although steroids also hold certain risks facilitating ulcer development. Pulse dosing of greater than $1000 \mathrm{mg}$ equivalent of prednisone, duration of high dose therapy exceeding 30 days and prior history of PUD are risk factors for steroid-induced ulcer disease [29]. Additional risk from the use of steroids comes from their ability to mask symptoms of ulcer development and cause a delay in treatment which may lead to perforation. The coadministration of corticosteroids and NSAIDs increases the risk of ulcer disease. Griffin's study showed additional risks when combining anticoagulation, NSAIDs and steroids and it showed that any combination of two of these agents cause an increase risk of ulcer development [28]. As mentioned above, it is uncertain how, if at all, SLE by itself plays a role in gastritis and PUD. A Russian study compared gastric biopsies in 27 children with SLE against 12 with chronic gastroduodenitis and found the children with SLE had more inflammatory changes in the mucosa, including higher levels of fibroblasts and small vessel IgG immune complex deposition during periods of disease flare [30]. While the significance of these findings does not quantify the degree of association with ulcer disease, it does suppose that some risk for gastric lining compromise extends from SLE beyond the use of high risk medications.

Gastric disease in SLE extends beyond gastritis and PUD. A link between Pernicious Anemia (PA) and SLE was investigated by Junca who found that while cobalamine levels were fairly low in a significant number of SLE patients (23\%), anti-intrinsic factor antibodies were present in only $3 / 30$ SLE patients and 0/45 controls [31]. This suggested an association of uncertain significance between SLE and PA and suggested only a minority of cases of B-12 deficiency in SLE would be related to the anti-intrinsic factor antibody. Gastric pathology in SLE can also include watermelon stomach. Although the condition, (caused typically by gastric vascular ectasia) is much more frequent in scleroderma, there have been case reports documenting its occurrence in SLE and association with iron deficiency and vitiligo [32]. Another rare association of hyperplastic gastropathy is noted in a single case report of patient with SLE [33]. 


\section{Intestines}

\section{Motility Disorders}

SLE has several motility-related disorders that tend to give patients a wide array of symptoms ranging from abdominal pain and bloating to nausea, vomiting and constipation. Chronic intestinal pseudo-obstruction (CIPO) is defined as a disorder of intestinal peristalsis with resulting ineffective bowel propulsion causing the aforementioned symptoms. The syndrome has been associated with SLE in several studies and case reports and typically abdominal pain is usually the most common presenting symptom [34]. Patients usually present with exam findings of distention and tenderness without rebound or rigidity with radiographic findings of dilated bowel loops, air fluid levels and absent bowel sounds. CIPO in SLE patients has been linked to genitorurinary complaints of dysuria and frequency resulting from cystitis and ureteral dilations, an association that has been suggested as being prognostic of a more complicated course of overall disease [35]. Mok's study of CIPO in SLE showed the existence of bilateral ureteral dilation or hydronephrosis with no infectious or obstructive origin in $12 / 18$ patients [36]. The findings and associations suggest a problem exists that may be either smooth muscle or neurogenic (enteric or autonomic) in origin. A case report detailed the presence of SLE, CIPO and pancreatic duct dilation of non-obstructive origin [37]. An investigation by Perlemuter presented the novel idea of using esophageal and intestinal manometry to evaluate the motility problem of CIPO in five patients with SLE. The study found four patients with intestinal hypomotility, three patients with esophageal dysmotility and four patients with bladder dysfunction or ureter dilation. Pathology on autopsy of one patient that died during the study showed fibrosis of the intestinal muscularis layer suggesting a myogenic origin [38]. Additional studies also suggest a muscular source and small vessel vasculitis as a potential origin to CIPO $[35,36]$. A true diagnosis requires a laparotomy and intestinal biopsy, a procedure most clinicians are unwilling to perform in an SLE patient, especially when already with signs of obstruction. Treatment of CIPO in the study by Perlemuter was generally with high dose IV steroids, pro-motility drugs and bowel rest. TPN and antibiotics were also used when needed. The results for most cases were positive with near complete remission of GI and GU symptoms in all patients [38]. Studies isolating the benefit of just pro-motility agents showed less of an efficacious response [34].

\section{Inflammatory Bowel Disorders}

The bowel can have a large variety of inflammatory processes that range from segmental to diffuse and involve all parts from the duodenum to the rectum. Lupus enteritis is inflammation of the small bowel and a common cause of abdominal pain which is further manifested by symptoms of nausea, vomiting and diarrhea. Lee's study noted enteritis of the jejunum and ileum as the most common cause of abdominal pain in SLE patients seeking emergency room treatment [39]. Examination will show tenderness and abdominal radiography can show a potential ileus on xray, edema of the wall in a distinct "accordion-like" appearance on ultrasound or a target-like lesion on CT scan [40]. Lee compared SLE enteritis patients against those with abdomi- nal pain and no enteritis and found no difference in serologic tests such as inflammatory markers or antibody patterns [39]. Enteritis may be partially distinguished by the rapidity of its onset. Kishimoto uses the term "acute gastrointestinal distress syndrome" (AGDS) to describe the severe, recurrent pain in two patients with noted small bowel edema on CT [41]. Even with the presence of a rapid onset and inflammation on radiography, the vague symptoms and lab findings it presents with traditionally makes diagnosis difficult. Enteritis is broadly felt to be associated with a form of small vessel vasculitis [40] and capillary leak syndrome [41]. The bowel inflammation has a tendency to recur, although other causes do exist, such as 2 cases of eosinophilic enteritis presented by Sunkureddi [42]. The inflammation responds well to pulse steroids with near to complete resolution of symptoms in most case series [43].

Inflammation of the colon distinctly originating from SLE is not common. Those ulcers that do occur tend to occur distally in the sigmoid and rectal areas [44]. Patients also present with complaints of abdominal pain but have a predominance of bowel symptoms such as bleeding and diarrhea. Lesions also tend to occur in early disease and have been reported as being the initial manifestation of SLE [43]. It can be difficult to determine if these colonic lesions are from SLE or ulcerative colitis as lesions look similar and both disease do co-exist. DMARD therapy leaves SLE patients prone to viral infectious such as CMV which should be considered in those with abdominal pain and colonic bleeding [17]. High dose IV steroids are traditionally first-line therapy with cytoxan also having strong efficacy [43].

The presence of SLE with inflammatory bowel disease is a frequently questioned but rarely associated phenomenon. The association of SLE and ulcerative colitis is highly uncommon and is only documented in a limited number of case reports. Dubois had a connection in $2 / 520$ of his patients [45]. Hallegua found an association in 2/464 patients of his own patients and reports on several others in the literature and noted in most the colitis preceded the onset of SLE [12]. Sulfasalazine is commonly first line therapy in controlling ulcerative colitis (UC) and associations have been made implicating this agent in causing lupus-like reactions [46]. A study by Gunnarsson noted 11 patients who developed SLE after starting sulfasalazine and noticed a direct correlation between longer duration of therapy, higher dosing and increased lupus severity [47]. This does not appear to simply be a drug-induced lupus as double-stranded DNA antibodies are positive (not typically seen in drug-induced lupus) and 4/11 of his reported patients still have active disease three years after drug discontinuation. Case reports do exist marking the development of SLE before UC, as well [48]. As noted above, it is difficult to differentiate ulcerative colitis from vasculitic lesions of SLE and the added complication of sulfasalazine-induced lupus further muddles the clinical presentation. Stevens recommends checking for active inflammatory markers (complement levels) and the presence of autoantibodies (SSA, SSB, anti-phospholipid) as abnormal results are not typically found in ulcerative colitis. He also suggests that haplotypes (such as HLA DR3 seen more commonly in SLE) can help differentiate the two processes [48]. 
The simultaneous occurrence of SLE and Crohn's disease is even rarer than that seen with UC. Hallegua notes only 9 such patients and since the review only sporadic case reports have been seen. Nonetheless, he describes the presence of an intriguing association between the two given the often presence of joint manifestations in Crohns and tendency for both conditions to improve on many of the same anti-inflammatory medicines [12].

Collagenous colitis is a chronic intestinal inflammatory disorder consisting of sub-epithelial deposits of collagen and lymphocytic infiltration. Currently it occasionally overlaps with SLE with an undetermined association as seen in several case reports [49]. Patients present with watery diarrhea and despite the bowel thickening typically seen in this disease have fairly normal radiographic studies and endoscopies $[8,50]$. Diagnosis typically requires a histologic analysis as macroscopically the colon may appear normal. Positive tissue samples will show a distinct sub-epithelial collagen band and inflammatory cell infiltrate in the lamina propria [51]. Prednisone and sulfasalazine are the treatments of choice for this condition.

\section{Malabsorption}

Protein loosing enteropathy (PLE) is defined as a loss of serum proteins through the GI tract leading to total body deficits of protein and resulting in reduced oncotic pressures and anasarca. The association of PLE with SLE has been known for decades but research interest in the connection has only recently elucidated some solid trends. Patients typically are young women who present with profound albumin deficits and generalized edema as in Perednia's review of 14 cases [52]. A more recent study by Mok confirmed these trends in 16 cases of SLE and PLE, noting fifteen of the patients were women and 12 presented with PLE as their initial SLE manifestation [53]. PLE can be the presenting sign of SLE, as in a retrospective study by Zheng in which $8 / 15$ patients reviewed presented with effusions and low serum albumin levels [54]. Several case reports have detailed more obscure associations accompanying and SLE and PLE combination, including Primary Sclerosing Cholangitis (PSC) with symptoms of neuro-psychiatric lupus [55], and interstitial cystitis with ileus [56].

The physical exam of PLE is significant for fluid overload and findings of effusions, especially pericardial fluid collections, is not uncommon. Diagnosis starts by finding a low serum level of albumin and then eliminating more common causes of hypoalbuminemia. Ruling out SLE sequelae such as renal disease, malnutrition or overt liver disease is required before PLE can be considered. Pericardial or pleural effusions, ascites and other signs of fluid overload are often present on physical exam at the time of diagnosis [54]. Serologic markers such as anti-RNP, high ANA and low complement levels have been reported [57, 58]. Diagnosis is aided by ingestion and measurement radio-labeled albumin or with newer methods such as measurement of stool losses of alpha-one-antitrypsin, a liver-manufactured protein with a molecular weight comparable to albumin [8]. The efficacy of these tests in SLE has been verified in several case reports [59-61] including the larger reviews by Peredina and Mok $[51,52]$. Radiographic evidence on barium studies can be seen with prominent edema of the mucosal layer with sacculation and fragmentation [8]. Hizawa added PLE can also be distinguished from pure enteritis by finding mildly thickened intestinal folds and the presence of submucosal nodules on X-ray [62].

Treatment of PLE in SLE centers around corticosteroids in most case reports with almost universal efficacy with the addition of an immuno-modulator if needed. Mok's study noted a sustained 6 month response in 14/16 patients treated with pulse steroids and azathioprine [53]. A case report showing refractory disease to these two medicines showed resolution with cyclophosphamide [63].

Several other malabsorptive processes have been linked to SLE. Fat malabsorption with a positive sudan black stain of the stool has been seen with SLE in a case report and was presumed to be caused by intestinal villous blunting secondary to immune complex deposition [64]. Mader had similar findings in his study of 21 randomly selected patients investigated for fat malabsorption with stool studies and intestinal biopsies. In those $2 / 21$ patients complaining of prior pain and diarrhea, both had evidence of stool fat malabsorption while one had evidence of villous blunting and inflammatory infiltrate on duodenal biopsy [65]. Both papers suggest SLE patients complaining of excessive diarrhea or bloating should be evaluated for fat malabsorption.

Celiac disease has occurred in 14 case reports simultaneously with lupus [66] and a possible link has been established between the common haplotypes HLA DR3 and HLA B8 seen in both diseases [67]. A case report detailed the combination of a rash determined to be dermatitis herpetiformis associated with celiac disease and the latter development of SLE [68]. A case series from the Mayo Clinic supported the association of the skin rash with SLE by citing 7 similar cases and again speculated the overlap may be related to similar HLA haplotypes seen in both diseases [69]. Sultan noted that when the association of celiac disease with SLE did occur, patient symptoms were well controlled on a gluten-free diet alone. Refractory cases were easily treated with steroids [8].

SLE has a diverse range of effects through the intestinal tract that includes derangements in motility, absorption, deposition and inflammation. Because patients often present with similar symptoms, the clinician must rely heavily upon clinical, radiographic and serologic associations to determine the etiology of a patient's complaints. Disorders of motility such as CIPO often present with pain as the presiding complaint with dilated bowel on CT scan and sometimes associations with GU dysfunction. Lupus enteritis and SLE associated with UC and Crohn's disease are associated with pain and diarrhea and may require visualization with radiographic imaging or colonoscopy with biopsy to differentiate from PLE, which may present in a similar manner.

\section{Peritoneum}

Peritonitis is a form of serositis and carries a wide range of presentations from asymptomatic ascites, intermittent abdominal pain and as in one case report, even masquerade as an acute abdomen with rigidity, rebound and guarding [35]. Hallegua estimates ascites to occur in $8-11 \%$ of lupus patients [12]. Multiple causes such as nephrotic syndrome, infections, pancreatitis, congestive heart failure, malignancy and liver disease among many others can cause fluid accu- 
mulation and thus must be explored as potential causes of ascites [70]. Lupus serositis causes an inflammation of the peritoneum resulting in an inflammatory, exudative ascites found on paracentesis. Because of their symptoms and chronic immuno-suppression, lupus patients with peritonitis and ascites should have their fluid sent for cell counts and culture. Although lupus is hard to diagnose from ascitic fluid, several case reports demonstrate that patients suspicious for SLE and a presenting symptom of serositis can have LE cells in ascitic fluid [71, 72]. Immune complexes, antibodies and low levels of complement can also be seen in the ascites [73]. Serositis can appear on imaging studies in several ways. Small bowel series can potentially show tethering, angulation and obstruction [74]. CT can clearly show the presence of ascites but also sometimes demonstrates asymmetric bowel thickening. Sometimes patients present with such severe peritoneal signs they are taken to surgery. In such cases, exploratory laparotomy may show a plaquelike appearance of the peritoneum if lupus inflammatory disease is present. Pain symptoms and fluid accumulation is usually responsive to steroid treatment. If recovery is slow, case reports have shown immunomodulatory drugs such as azathioprine [75] or cyclophosphamide [76] can supplement the glucocorticoids. Diuresis can help with simple fluid management. Recurrent or chronic peritonitis responds to steroids with lower efficacy than the acute form and is associated with effusions outside the abdomen [77].

\section{Pancreas}

Pancreatitis is an important and possibly often under diagnosed complication of abdominal pain in SLE. Patients can have many acute or chronic forms and variation is seen in severity ranging from mild, self-limiting disease to fulminant failure. The incidence of pancreatitis in the generalized population of SLE is rare with frequency estimates ranging from $0.4-1.1 / 1000$ [78]. Derk found 1\% of SLE patients had the diagnosis of pancreatitis made on hospital presentations for various reasons [79]. Patients presenting with pancreatitis as their first manifestation of lupus have been noted in several case reports but the frequency is very rare and only a small handful appear in the literature $[80,81]$. Pancreatitis appears to be more common in woman and patients of younger age. In Breuer's analysis of 27 patients with lupusrelated pancretitis, $88 \%$ were female with a median age of 27 [78]. An evaluation of gastrointestinal manifestations in 39 pediatric SLE patients noted 8 had evidence of pancreatitis at diagnosis and an additional 4 patients contracted symptoms shortly thereafter [82]. Adult patients afflicted with this complication are often noted to have a long history of active SLE with additional organ involvement and on longstanding aggressive medical therapy [83].

The presentation of pancreatitis in SLE follows the typical symptom pattern of abdominal pain, nausea and vomiting with a physical exam significant for epigastric tenderness. Diagnosis is aided by laboratory evaluation with amylase, lipase, blood counts and liver function tests. In most cases the clinician can make an accurate assessment based on clinical and laboratory findings. In some patients, however, pancreatic inflammation occurs in the setting of normal lab markers. These cases require further objective findings and radiography is often used. Standard CT scans having a sensitivity of $70-90 \%$ in diagnosing pancreatitis while ultrasound has a sensitivity of $60 \%$ [84] although they have not always proven effective in lupus-specific studies [85]. Diagnosis also requires careful consideration of other potential causes of pancreatic inflammation, especially in a lupus patient with active disease on potent, chronic immuno-suppressive medications. Drugs, infections, diabetes, malignancy, coronary artery disease and cholesterol among many others are risks to all lupus patients and are potential causes of pancreatitis that must be ruled out. Most cases of lupus pancreatitis are also likely related to the same normal causes seen in the general population such as gallbladder and liver disease, alcohol and dehydration [79].

The level of disease activity can be difficult to distinguish from exam and labs alone. Amylase levels have been proven to be elevated in lupus patients without any clinical or radiographic evidence of disease. Ranson noticed a high amylase level in $30.5 \%$ of patients with absolutely no clinical symptoms [86]. The postulation is thus made that subclinical activity and chronic damage may occur without the patient or clinician knowing [83, 86]. Hasselbacher measured the amylase level in 25 asymptomatic patients with SLE and 15 controls and found the average amylase level in SLE patients was significantly higher at baseline than the general population [87]. The significance for this finding in a lupus patient by a clinician is not clearly known. Frank noted many possible sources for the sub-clinical elevation such as uremia, infections, dehydration, diabetes and vascular diseases. Even circulating auto-antibodies (anti-islet cell anti-bodies) can cause amylase elevations [84]. Currently studies evaluating the long term significance of sub-clinical hyperamylasemia in SLE do not currently exist.

A definitive cause of pancreatic inflammation resulting directly from lupus activity is not currently known. It is known that pancreatitis occurs during SLE flares and Nesher found mortality from pancreatitis increases with disease activity and serum inflammatory markers [85]. Pancreas involvement can occur during SLE remission and some suggest organ specific inflammation is actually more common when other lupus features are quiescent [88]. A strong speculation among some authors links pancreatitis to a lupusinduced vasculitis $[89,90]$. Another theory is that the circulating immunoglobulins and lymphocytic infiltration could directly induce the inflammation [91]. Anti-phospholipid antibody syndrome has also been implicated by its potential for focal clots and micro-thrombi formation. Petri argues against this as a possibility given the lack of clots found in pancreatic vasculature of symptomatic patients on autopsy and by asserting other causes explaining micro-thrombi presence are more likely [88].

The role of glucocorticoids in inducing pancreatitis has long been debated. Earlier studies mentioned a connection between the use of steroids and risks for developing pancreatitis [92-94]. Recent reports have presented data attempting to negate these findings $[89,95]$. Saab's retrospective study of 8 cases noted improvement in all patients after receiving steroids and concluded their use was important in treating SLE related pancreatitis [96]. Duncan argues against the indictment of steroids citing the rarity of pancreatitis in non-SLE patients taking them for other diseases and further cites the examples of pancreatitis as a presentation of SLE before steroids were given [80]. 
All suspicions of pancreatitis must be thoroughly evaluated and addressed given the dire complications and often fatal outcomes of this complication of lupus [97]. Treatment of acute pancreatitis requires allowing the patient nothing by mouth, fluid hydration and the obvious discontinuation of any possible offending drugs. Treatment with steroids can begin when other possible inciting events have been ruled out. Nesher reported the importance of aggressive treatment by comparing mortality rates in steroid treated and untreated SLE patients with pancreatitis. He found a significant reduction in mortality in those given glucocorticoids $(20 \%)$ versus those who had them withheld $(61 \%)$ [85]. In Beuer's 27 patient study, he found mortality was reduced by $67 \%$ with the early administration of steroids [78].

Chronic pancreatitis is also seen in the context of SLE albeit in a much lower frequency limited to case reports. Patients range in age from adults to children and are described as having recurrent bouts of pancreatitis with eventual loss of organ function through scarring and diffuse calcifications [91, 98]. Chronic disease of the pancreas also has no definitive cause in lupus patients. Penalva suggests medicines such as azathioprine and steroids may be related and also notes a wide range of others causes including genetic predisposition and frequent episodes of lupus-related inflammation [91]. Hortas presents a case report of pancreatic calcification and pseudocyst and speculates the connective tissue disease can directly cause the alterations of calcium deposition seen within chronic pancreatitis [99].

\section{Vasculitis}

Vasculitis involving the various vessels of the GI system is a rare but potentially deadly complication of SLE. It can affect every portion of the GI tract from the esophagus to the rectum. Vasculitis presenting exclusively in the GI tract is not as common as its cutaneous manifestations. The incidence of gastrointestinal vasculitis in the general lupus population is estimated at less than $1 \%$. Vitali found $1.1 \%$ of a sample group of 704 patients had intestinal vasculitis [100] while the review by Sultan quoted the incidence from a population of 266 SLE patients at $0.4 \%$ [8]. Drenkard looked specifically for vasculitis in a cohort of lupus patients and found only $1(0.2 \%)$ with mesenteric vessel inflammation [101]. In patients presenting with severe abdominal pain, however, the incidence rises very quickly. Medina's investigation into the causes of acute abdomen in lupus found 19/51 patients had vasculitic lesions on pathology [102]. Nadorra's report on the autopsies of 26 children with SLE noted the common finding of ischemic bowel lesions and found $60 \%$ were directly related to vessel-based inflammation [21]. Those affected by vasculitis tend to be young males and had a longer course of SLE with more activity at baseline. Associations are noted with anti-phospholipid antibody syndrome, pleurisy, serositis and secondary Raynaud's phenomenon [101].

While the range of symptoms can be very non-specific, patients with lupus-related vasculitis often are very toxic in appearance and have evidence of vessel inflammation in other parts of the body such as skin, kidneys and the CNS [8]. Abdominal pain with nausea, vomiting and signs of bleeding are common early manifestations [103]. Bloating, anorexia, abdominal fullness can also been seen. Esophageal involvement can present with dysphagia. Vasculitic colon lesions are associated with diarrhea, melena and hematochezia [35]. There is always a possibility for a vasculitic lesion to perforate and so subjective complaints of severe abdominal pain or fevers and shaking chills must raise immediate suspicion for acute abdomen and prompt further aggressive diagnostic measures. Luman notes patients also have generalized activity of their lupus during vasculitic episodes [35]. Medina's study found patients presenting with acute abdomen and a high disease activity index (SLEDAI) significantly predicted its involvement in the abdominal process and suggested using SLEDAI as a diagnostic tool in these circumstances [102]. Buck studied patients with subacute abdominal pain and found those presenting with vasculitis were more likely to have an SLEDAI score over 8 [104]. Activity of SLE in the presence of abdominal pain during a flare of SLE-related pancreatic inflammation has been verified in other studies [105].

Physical exam can also vary widely from the moderately and diffusely tender to the rigid with rebound, guarding and peritoneal signs. Labs should be checked for cell counts, liver function and coagulation studies. Low platelets and low complement may be immediate tests to help isolate lupus as a potential cause when vasculitis is suspected. Acidosis, lactate and instability of a patient's vital signs suggest perforation and urge rapid management. A differential diagnosis at the bedside of such patients must be broad and should include all causes of vessel ischemia, peritonitis, inflammatory bowel disease, infectious colitis among other causes. Lupusrelated vasculitis can often be misdiagnosed as gastritis, PUD or enteritis [8] and has been mistaken for bowel obstruction and peritonitis [106]. Ascites is often a common finding in patients with mesenteric or other vascular inflammation [106, 107]. Paracentesis can help diagnostically by showing the presence of overt bleeding or infection if ascites is present.

Radiographic studies can be quite useful in diagnosing vasculitis of the GI tract. Plain film xrays are not helpful in diagnosing bowel ischemia but are a necessary first step to rule out perforation and the presence of free air. Barium enema can show thumbprinting consistent with bowel wall edema. CT scans are a key diagnostic tool and several studies note their enhanced ability to detail areas of bowel thickening and vascular engorgement that can be consistent with vasculitis [106]. Taourel investigated the use of the CT scan in diagnosing mesenteric ischemia and found areas of dilated bowel and bowel enhancements (target and halo signs) were common in patients with mesenteric ischemia. In a controlled study, he found the contrast enhanced CT was highly specific (92\%) and resulted in a diagnostic accuracy of $75 \%$ for evaluating the presence of mesenteric ischemia [108]. Ko similarly measured the efficacy of CT by looking at patients with confirmed mesenteric vasculitis and noting common radiographic patterns. Enhancing ascites, bowel thickening and halo/target signs were seen. A palisade or comb like pattern representing prominent vasculature supplying dilated bowel loops was concluded to be a potential early sign of disease [109]. Gas collection in the bowel and fat attenuation can also be seen on CT scan [106]. CT scans are not overly specific with these signs and findings can overlap with enteritis, IBD or low albumin states although they are also good at detecting infection, metastases and other diseases 
that can confound a differential diagnosis. Non-linear involvement of the bowel can also represent inflammation of multiple vessels and can be a more specific marker of true vasculitis [39]. Angiograms to diagnose and demarcate involvement are not often helpful in lupus-related vasculitis. Disease predilection is often for the small vessels of the mesentery and thus lesions are not usually visible on traditional angiograms [110]. When physical exam and radiographic studies still leave the diagnosis of gastrointestinal vasculitis uncertain in the lupus patient, direct visualization and biopsy and/or excision of suspicious lesions is the next appropriate step. Grimbacher suggests the work up of suspected lupus-related GI vasculitis to always start with CT scans and then to proceed to visualization with endoscopy/ colonoscopy and exploratory laparotomy if warranted [70]. Several case reports support the utility of colonoscopy in evaluating a patient with the signs and symptoms of a compromise to bowel wall integrity. Intestinal wall ischemia will often show discrete, "punched-out" lesions of varying size and depth with surrounding edema [70]. Surgical exploration is also efficacious and ischemic lesions are often easy to identify. Pathologic specimens taken from endoscopic or surgical biopsy typically show the involvement of the small vessels. The adventia and media of these vessels show complement, immune complex and fibrinogen deposition with cellular infiltrate of neutrophils, plasma cells and lymphocytes consistent with chronic inflammation [70]. Degeneration of the media, thrombosis, intimal proliferation and fibrinoid necrosis of vessel walls have also been described [8, $110,111]$.

Vasculitis in SLE can occur anywhere in the gut vasculature and lesions have been reported in pancreas, gallbladder and throughout the length of the bowel. The small bowel is typically more common but lesions have been frequently detected in the colon, as well [35]. Although isolated involvement of the rectum is not common because of the plethora of vessels supplying the area [106], several case reports of SLE patients exist documenting the presence of isolated rectal ulcers and perforations resulting from focal vasculitis [112-114] and another noted this complication as the presenting sign of lupus [115]. Zizic noted in his study of lupus patients with acute abdomens that abdominal vasculitis typically affected the small vasculature in preference to the medium sized or larger vessels [116]. There are some suggestions that the superior mesenteric artery and its branches are more often involved [117]. A case report profiling superior mesenteric artery involvement in lupus also suggests ischemic lesions may appear as aneurysms [118].

Lupus related vasculitis can also cause an isolated inflammation of the venous system with exclusion of arterial involvement. The rare phenomenon has been named mesenteric inflammatory veno-occlusive disease (MIVOD). Case series data show the rare incidence and only isolated case reports of activity in lupus exist [119]. An association with APAS has also been reported [120]. MIVOD is vein inflammation characterized by bouts of abdominal pain with physical exam and laboratory findings similar to arterial vasculitis. Surgical exploration finds necrotic and ischemic bowel with normal arteries [121]. Pathology typically reveals inflammation of the venous system with lymphocytic, necrotizing and granulomatous disease [122]. Thrombosis is often associated in affected areas secondary to the inflamma- tory process and its presence can erroneously overshadow the venulitis. Careful attempts must be made to differentiate MIVOD from mesenteric vein thrombosis or other hypercoagulable states [123].

Treatment of any vasculitis is an urgent issue and delayed recognition or treatment of abdominal related disease will have been proven to significantly affect patient morbidity and mortality [35]. Delays in care risk bleeding and perforation in the gut and increase the chances of lesions appearing in other organs. As noted, the mortality of SLE patients presenting with acute surgical abdomens is dismal with mortality rates often approaching and exceeding $50 \%$ in most reports $[116,124]$. Treatment is aggressive and often involves immediate assessment for intestinal perforation. Bowel rest with nothing by mouth and IV fluid hydration are the suggested initial therapy. Sultan notes small bowel ischemic lesions are more apt to ulcerate and perforate, often necessitating surgery. Large bowel lesions are typically more stable and may be approached in a more conservative manner with a "watch and wait" approach [8]. If perforation is suspected at any point, surgical exploration and resection with antibiotic administration is required. After resolution of the acute issues, the need for steroids can be addressed. Sultan and Hiraishi both note the common use of glucocorticoids in lupus-related gastrointestinal vasculitis but state their use is often based on case reports [103]. In addition, non-steroid immuno-suppressive therapy in these patients also lacks significant literature attention [8]. Case reports on the use of cyclophosphamide, plasmapheresis [125] and rituximab [126] exist but definitive and unified management approaches have yet to be established.

\section{Abdominal Pain}

Generalized symptoms of abdominal discomfort and pain are very common in lupus and a differential diagnosis often includes many of the subjects discussed above. A special mention is made of them here because of their frequency and also the potential for symptoms to represent a severe and life-threatening process. Nausea, vomiting and anorexia are common complaints in lupus patients with symptoms often peaking during evidence of active disease. However, given patient medication profiles and subsequent infection risks and the presence of symptoms during disease quiescence, the cause and overall significance of these complaints can be difficult to decipher. For example, Hallegua notes while the frequency of nausea occurs in a range of $11-38 \%$ of patients, this number drops to $8 \%$ after the exclusion of medications [12].

Abdominal pain occurs in a frequency of $8 \%$ to $37 \%$ and is an equally difficult entity to evaluate $[12,124]$. The frequency and presentation is similar in the pediatric population [8]. Symptoms can range from mild discomfort and cramping to the extreme of severe and incapacitating pain reflecting a very broad range of diagnoses. Patients with mild to moderate abdominal complaints often present with chronic pains of insidious onset. In such cases usually presenting to the outpatient office, patients are likely to have nonemergent conditions such as medication intolerance, gastritis, serositis or bacterial overgrowth [35, 127]. Simple diagnostic tests such as the lactulose hydrogen breath test for bacterial overgrowth diagnosis or treatments such as simple 
medication changes or antacids can be tried before more invasive diagnostic tests are employed. Those presenting with more acute and severe pain or seeking emergency treatment must be approached aggressively, especially if symptoms occur with nausea, vomiting, fevers or signs of an acute abdomen. Studies profiling such presentations demonstrate the many potentially disastrous consequences that can occur in these patients. Al-Hakeem review of 13 lupus patients presenting to the emergency room with abdominal pain found 9 needed emergent surgeries [128]. Lian noted of 52 patients with hospital admission for abdominal pain and associated symptoms, $63 \%$ had serotitis or other bowel involvement [129]. Zizic's study demonstrated the staggering morbidity/ mortality by looking at 140 SLE patients seeking emergency care for abdominal pain and finding $15(11 \%)$ with signs and symptoms of acute abdomen with over a $50 \%$ (8/15) associated mortality [116].

Causes of such severe pain can be directly associated with lupus related sequelae such as vasculitis, ulcerations or thrombosis and can present as pancreatitis, peritonitis, aneurysms, enteritis or bowel/ organ infarction and perforation. Those causes unrelated to auto-inflammation such as cholecystitis, appendicitis, adhesions, infectious gastroenteritis are also common in SLE patients and must not be ignored when conducting evaluations of abdominal pain [102]. The acute abdomen requiring emergent surgery may result from almost any of the above and is likely the most feared complication presenting with abdominal pain. Richer's study of pediatric patients with newly diagnosed SLE noted 5/39 patients required exploratory laparotomy for significant abdominal pain [82]. Medina noted 3/51 patients with a perforated duodenal ulcer in his review [102] while Al-Hakeem found 2/9 patients presented with acute abdomen and perforated bowel [128]. Symptoms may often be blunted given the degree of steroid-related immuno-suppression.

Diagnosis begins by retaining a broad differential diagnosis, including inflammatory as well as structural causes of disease. Evaluating the presence of active SLE may help in narrowing a spectrum of causes. There is an unknown association between lupus activity and risk for serious abdominal complications. Medina's study found a higher SLEDAI was more predictive of large peri-operative mortality in an acute abdomen and that low disease activity scores were significant in predicting the absence of lupusrelated abdominal disease [102]. Lee and Moon looked at 38 patients with abdominal pain and found SLEDAI scores were not predictive of SLE involvement in gut pathology [39]. Blood counts, liver function tests, pancreatic enzymes and lactate levels should be ordered and abdominal radiography should focus on ruling out the presence of free air. The role of the CT scan in ruling out an acute abdomen in SLE patients is unclear but remains useful as signs of focal vasculitis or bowel inflammation can be visualized [35, 130]. Medina recommends paracentesis and eventual exploratory laparotomy in evaluating lupus patients with persistent symptoms and an unclear diagnosis after completing the initial workup [102]. The decision to send patients to the operating room is often a resisted one and difficult cases can be tempting to resort to using conservative measures such as bowel rest, fluid hydration or even steroids. Patients with SLE statistically do not tolerate surgery well, often forming adhesions [131] and being at risk for peri-operative infections. Lee noted abdominal pain in dominal pain in non-emergent cases can take a long time to resolve and can complicate the decision to send patients to surgery [39]. Koh's study attempting to elucidate correlations between patient presentation and surgical necessity was not successful in finding significance in lab or radiographic results [132]. However, studies clearly categorize lupus patients as high risk and urging invasive management not to be delayed. Zizic found lupus patients already waited an average of 34 days before seeking treatment and presented in life-threatening crisis as a result [116]. Medina's investigation found delayed surgical management resulted in a significantly worsened mortality [102]. Decisions must be made on a case by case basis using the combination of symptoms and background lupus activity, exam, lab/ x-ray evaluation and often the less descript physician intuition with mindful consideration not to delay intervention extensively.

\section{Liver}

Liver disease in SLE is a difficult entity to classify and can range from benign laboratory elevations to severe inflammation and organ failure. Overall dysfunction can occur within a large portion of lupus patients with estimates as high as $21-55 \%$ by Yamasaki [133]. While Matsumoto showed the majority of liver disease present in SLE is a result of passive congestion or fatty infiltration [134], potential causes are many and can include disease related hepatitis, drug toxicities, thrombotic events, infections and other associated auto-immune conditions. In general, hepatic involvement in lupus is often only mild to moderate with only mild to moderate clinical consequences for the patient. Hallegua quoted $10-32 \%$ of patients will present at some point with hepatomegaly [12] while in Abraham's review of several studies a slightly higher and wider range for enlarged livers was detailed (12-55\%) [135]. Risk factors for development of generalized hepatic disease in lupus include the presence of oral ulcerations, cytopenias, thyroid disease and the presence of double stranded DNA antibodies [136]. The concurrent presence of arthralgias and liver disease in SLE is less common. Specifics of the variability of presentations of liver dysfunction are found below.

\section{Liver Function Test Abnormalities}

Liver function abnormalities are common in the SLE patient and are often of uncertain significance. Van Hoek's review predicted a $25-50 \%$ lifetime chance of abnormal liver enzymes exclusive of such causes as myositis or hemolysis [137]. Suzuki presented a randomized survey of 193 lupus patients and found 78 cases $(40.4 \%)$ with elevated transanimase levels; 35 patients of the 78 with abnormal liver enzymes were diagnosed with identifiable liver disease [138]. Runyon conducted a retrospective study of 238 patients and found 124 had at least one abnormality of the liver function test with 43 meeting criteria for an existing liver disease [139]. In a large, prospective study of 260 randomly selected lupus patients, $23 \%$ were found with LFT elevations [140].

Despite being relatively common, elevated liver enzymes in SLE are rarely related to clinically significant disease. Patients often lack associated clinical symptoms and liver enzyme abnormalities are found by chance, making the significance of subclinical disease and its relationship to SLE difficult to ascertain. The enzyme elevations often may be directly related to medications such as steroid use, metho- 
trexate, NSAIDs, azathioprine or aspirin [137] and often correct with drug withdrawal. Liver enzyme abnormalities may also result from secondary consequences of lupus such as passive hepatic congestion, cholestasis, fatty infiltration of the liver or related autoimmune disease of primary hepatic origin [133] and their treatment is simply directed towards resolving the inciting cause. In cases where the origins of the LFT elevations are not clear, attention must be paid through serial examinations, radiography and lab work to identify those cases that are related to true lupus-induced hepatic disease. Miller's review mentioned above found 12/15 patients with unexplained LFT elevation also had evidence of lupus activity [140]. Mok estimates as many as 20\% of SLE patients with abnormal LFTs have no identifiable cause for the abnormality, leaving SLE activity as a likely potential source [141]. These assessments are nicely summarized in Gibson's retrospective review of 81 randomly selected SLE patients which found 45 (55\%) with elevated liver enzymes at some point during the course of their disease; 14 of the 45 cases were related to medication use, 9 were related to extrahepatic causes and 19 were noted to have no identifiable explanation other than SLE [142]. Suzuki noted in his 9 discovered cases of lupus-induced liver inflammation the disease process was usually less severe than cases where other identifiable origins were associated such as fatty liver disease, AIH and PBC [138]. A full assessment of liver function should be made with lab screenings (amylase, lipase, GGT, hepatitis and infectious panel) autoimmune hepatitis antibody profile (see below), radiography (ultrasound, MRI) and possibly a hepatology consultation. To establish a link, attention should be paid to other signs of lupus activity such as associated symptoms typical of the patient's flare, complement and serologic antibody levels and the physical examination. Hallequa noted disease related specifically to lupus was more commonly lobular on pathologic examination and was associated with elevated serum levels of double stranded DNA [127]. A paucity of lymphoid infiltrates can also be seen on pathology specimens [133]. Anti-ribosomal P antibodies have also been associated with lupus-related liver disease. Hulsey's controlled study found 7 out of 20 patients with the antibody and documented SLE developed hepatic dysfunction compared to 1 out of 20 without the marker [143].

Lupus related liver inflammation can progress to chronic active hepatitis in a small number of patients. In a retrospective survey of 131 lupus patients, 4 were found with pathologic evidence of liver disease consistent with chronic active hepatitis [144]. Runyon's review found 4 out of 9 patients surveyed with serial biopsies showed progression of liver disease [139]. Matsumoto's autopsy registry review of 1468 patients suggested an incidence of chronic hepatitis in $2.4 \%$ of SLE patients with $1.1 \%$ progressing to cirrhosis and $0.8 \%$ developing fibrosis [145]. High titers of double stranded DNA, LE cells, anti-ribosomal $\mathrm{P}$ antibodies and a more aggressive disease process are noted risk factors for developing chronic hepatitis [144, 146, 147]. Treatment of hepatic function abnormalities linked purely to generalized lupus activity should be treated with steroids. Steroid sparing agents such as azathioprine and other DMARDs have also been shown to be effective and progress is gauged through serial hepatic function studies and clinical signs of lupus activity.

\section{Autoimmune Hepatitis}

Autoimmune Hepatitis (AIH) is a chronic necroinflammatory disorder of the liver associated with antibody production and hepatocyte destruction that is defined as a separate disease maintaining links to many other autoimmune conditions. The discovery of unique antibody and serologic markers allows the disease to be classified into three categories. Type 1 (originally termed "Lupoid hepatitis" by Mackay in the 1950s [148] is marked by the presence of anti-smooth muscle antibodies (AMSA) and has the most overlap associations with SLE. Type 2 AIH has anti-liver kidney mouse (LKM) antibodies; type $3 \mathrm{AIH}$ is associated with anti-soluble liver antigen (SLA). It is diagnosed by a scoring system originally created in 1993 and updated in 1999 and defines the presence of disease as "probable" or "definite" based upon hepatic function lab abnormalities, immunoglobulin levels, autoantibody profile, histology, response to treatment and the absence of confounding diagnoses such as viral hepatitis [149].

AIH often has extra-hepatic manifestations and frequently overlaps with connective tissue diseases. Patients typically present with non-specific complaints such as fatigue, constitutional symptoms and abdominal complaints such as cramps and changes in appetite; the insidious onset of signs and symptoms of autoimmunity such as arthralgias, fevers, elevated immuno-globulin levels and autoantibodies (ANA) are also present [141]. A diagnosis of AIH is obtained through a serologic antibody profile and with histologic evidence of interface hepatitis/ periportal cellular inflammation and necrosis, dense lymphoid infiltrates and rosetting of hepatic cells $[133,150,151]$.

Patients fulfilling criteria for both SLE and AIH are more common than previously thought. Several case reports exist detailing the overlap between SLE and AIH [133, 152, 153] and usually describe younger, female patients with mild to moderate lupus activity and lab analysis containing a strongly positive ANA, high titers of double stranded DNA and signs of chronic liver dysfunction. The difficulty in establishing the diagnosis in an SLE patient stems from both diseases presenting with very similar and often confounding clinical and laboratory manifestations [154]. Its presence in lupus patients makes it very difficult to ascertain when liver dysfunction is a result of auto-immune destruction from AIH or from SLE activity and its consequences. While the AIH criteria and scoring system have been verified several times in its specificity [155], documented cases do exist where an erroneous overlap of AIH and SLE was established by using purely the clinical and serologic criteria for a diagnosis [150, 153]. Weaknesses were shown in using the older 1993 criteria in patients with connective tissues diseases and McFarlane, the author of the original and revised criteria, retorts such examples show the vital importance of using liver histology in combination with the remaining criteria to differentiate or confirm the associated presence of AIH and SLE [150]. Treatment utilizes immuno-suppression often initially with prednisone although azathioprine has been reported to effectively induce remission [156]. Flares of the disease are common and recurrence frequently necessitates more potent options. Maintenance and steroid-sparing therapy with cyclosporine and mycophenolate mofetil have also been effectively described [157]. 


\section{Other Liver Diseases}

Nodular regenerative hyperplasia (NRH) is a distinct disease of hepatic origin that has shown an ill-defined relationship with SLE. It is characterized grossly by diffuse nodules through the liver with a normal liver architecture. The association with SLE is more common than previously believed. A study by Matsumoto found 5 out of 73 randomly selected SLE patients examined by autopsy or biopsy had evidence of NRH [134]. Patient presentation is vague with rare somatic complaints and often a normal liver function profile. Evidence of portal hypertension, varices and GI bleeding may be the only identifying signs [141]. Diagnosis can be aided by an abdominal MRI but confirmation requires a liver biopsy [158]. Pathology will show a non-cirrhotic architecture with hyperplasia of hepatocytes which form the nodules. NRH is associated with anti-phospholipid antibodies in SLE and there is an assumption that the nodules represent localized areas of repaired parenchyma resulting from ischemic injury related to a hypercoagulable state [141]. Klein's study compared the serum of NRH patients against 3 matched control groups (PBC, AIH and healthy patients) and found significant percentage $(77 \%)$ of those NRH had antiphospholipid antibody (specifically anti-cardiolipin antibody) [159]. Treatment is directed toward control of the resulting portal hypertension and its adverse effects.

The use of potent medications in treating SLE can often be marked by elevated liver enzymes and general signs and symptoms of liver dysfunction with effects can range from inconsequential lab abnormalities to fulminant hepatic failure. Steroid use has been documented to result in fatty liver infiltration with varying consequences [135]. Aspirin, NSAIDs, azathioprine and Methotraxate have been well documented in causing transient liver dysfunction in some SLE patients. Hydroxychloroquine (in rare cases) has also been linked to liver inflammation $[139,141]$. In a 1998 review, Angulo linked Minocycline to 60 cases of druginduced SLE, 24 cases of AIH and an additional 13 cases of overlapping symptoms including arthritis, elevated LFTs and a positive ANA [160]. Elkayam found a similar combination of AIH and symptoms of drug induced lupus in 66 patients who had been taking Minocycline, 63 of which had a positive ANA [161]. Both studies found the interesting absence of histone antibodies despite other signs and symptoms consistent with the traditional presentation of drug induced lupus. A few case reports have also linked the cholesterol lowering statin group to liver disease in SLE patients [162].

Thrombotic and thromboembolic disorders causing liver dysfunction have been documented in SLE and high risk patients can be identified by the presence of anti-phospholipid antibodies [141]. Disorders such as veno-occlusive disease and Budd-Chiari syndrome can occur during the hypercoagulable states seen in certain SLE patients. Case reports also exist documenting massive hepatic vasculature occlusions of both the arterial and venous systems [163]. Patients can present with laboratory results outside the normal range, generalized abdominal complaints or more specific symptoms of ascites, portal hypertension or cirrhosis. An inquiry detailing a history of prior clotting episodes or pregnancy loss should be obtained. Successful treatment of difficult cases often depends on the unique situation of the patient but case reports typically involve anti-coagulation usage and possibly steroids.

Fatty degeneration of the liver can be a very common finding in lupus with Matsumoto's autopsy study finding significant fat deposition in 38 out of 52 liver samples [145]. Although commonly associated with medications and more specifically chronic steroid administration, cases of diffuse fatty infiltration in the absence of systemic inflammation and corticosteroid exposure have been documented [164]. One such case actually showed improvement of fatty deposits with pulse steroid therapy. The risk for developing cavernous hemangiomas appears to be raised in SLE patients [165]. Rarer associations are seen in limited case reports such as severe amyloid deposition and hepatic dysfunction was documented in a 37 year old with lupus [166]. Another describes a case of fulminant liver disease and the death of a 12 year old girl resulting from the first reported association of lupus and Wilson's disease [167].

\section{Infectious Hepatitis}

The infection rates of hepatitis B in lupus patients are not increased when compared to the generalized population [141, 168]. Chung examined 76 randomly selected SLE patients and 100 controls and found the rates of past and present Hep B were identical [169]. Lu conducted a study on Hep B prevalence in the hyperendemic environment of Taiwan between 173 lupus patients and 692 matched controls. Infection rates among the lupus patients were significantly lower $(3.5 \%)$ when compared to the control group $14.7 \%$ [170]. Lupus patients infected with hepatitis B in this study also noted milder lupus activity with less proteinuria and lower antibody titers. Lu attempted to explain the difference by noting differences in the production of interferon alpha and gamma in those patients sharing lupus and Hepatitis B compared to lupus patients without the virus [170]. A suspected link associating Hepatitis B surface antigen with a pathogenetic role in lupus related renal disease was negated by Lai [171], although case reports have suggested a subset of SLE patients with HBV antigenemia may display an altered form of lupus glomerulopathy [172]. Prevention of HBV infection should be addressed and vaccination for hepatitis B virus in SLE patients has been deemed low risk and should be pursued in those who meet administration criteria [173].

Hallegua's review stated the estimated prevalence of Hepatitis $\mathrm{C}$ virus in lupus was about equal to the generalized population with a rate around 0.5 to $1 \%$ [127]. Early and more limited investigations on these infection rates showed no difference between lupus patients and the general population [168, 174].A more recent survey by Ramos-Casals matched 134 randomly selected SLE patients with 200 healthy donors and found confirmed HCV infection in $11 \%$ of those with lupus compared to $1 \%$ of controls [175]. A smaller study by Ahmed in 2006 found a 10\% infection rate among 40 surveyed lupus patients [176]. However, Kowdley noted in 1997 a strong potential for false positive results of Hepatitis $\mathrm{C}$ viremia in SLE patients undergoing ELISA and Immunoblot analysis. The study showed of 42 lupus patients surveyed by ELISA and Immunoblot, only 2 / 5 tested initially by ELISA and $1 / 3$ positive results by Immunoblot 
were confirmed positive with the subsequent PCR method, concluding that positive test results for Hep $\mathrm{C}$ must be confirmed by PCR in patients with SLE to avoid false positive results [177]. It is also not known if the elevated prevalence of dual disease is related to an unexplained potential Hepatitis $\mathrm{C}$ virus may hold to initiate lupus activity in those who were previously asymptomatic but genetically susceptible [176].

No definitive profile for the degree of lupus activity when combined with hepatitis $\mathrm{C}$ viremia has been established. By itself, Hepatitis C can mimic a diagnosis of SLE with arthralgias, myalgias and ANA positivity in ranges of $10-30 \%[176,178]$, a similarity requiring the clinician to decipher the true origin of the overlapping symptoms in patients afflicted with both conditions. Ahmed found no mitigation of disease in concomitant infection and SLE in his 40 patient study [176]. Ramos-Casals noticed milder skin disease, lower complement levels, higher double-stranded DNA titers, advancement of hepatic disease and significant cyroglobulinemia in those with the overlapping conditions [175]. Other similar studies also found higher risks for cutaneous vasculitis, the presence of anti-cardiolipin antibodies and rheumatoid factor, in patients with Hep C virus and lupus [127, 179]. Perlemuter also concluded that the immune hyperactivity of lupus or treatment of the disease with steroids does not worsen the course or effects of the hepatitis virus [180]. Treatment of HCV with interferon-alpha may worsen lupus symptoms with its potential to cause an SLElike syndrome. Wilson's review noted the literature has shown 4-19\% of patients receiving interferon-alpha therapy develop an auto-immune-like syndrome; lupus-like syndromes were seen in 13 reviewed case reports and included symptoms of fevers, arthralgias, serositis with high titers of ANA and double stranded DNA antibodies. Symptoms can occur within weeks to years following medication administration [181].

\section{Gallbladder and Bile Ducts}

Gallbladder disease in SLE has not been shown to occur with any altered frequency when compared to the generalized population [12]. While abdominal pain remains a typical and anticipated presenting feature, other ambiguous signs and symptoms of organ compromise can confound and delay a diagnosis. As in any acute abdomen workup, physical examination, labwork and ultrasonography and CT scans should be utilized to narrow a differential diagnosis. Similar clinical and radiographic features hold potential for cholecystitis in SLE to be mistaken for serositis[182] or other acute abdominal processes. Origins of the pathologic changes can be widespread with several case reports describing the presence of acalculous cholecystitis resulting from diffuse thrombotic events associated with anti-phospholipid syndrome [183] and isolated venous inflammation consistent with MIVOD [119]. Arterial vasculitis specific to the gallbladder vessels has also been detailed in several case reports $[184,185]$ it has been suggested vasculitis may show a predilection for the gallbladder because of its tenuous vascular supply [183]. Risk for developing acalculous cholecystitis is associated with burns, malignancy, trauma, TPN use, infection and prior episodes of vasculitis [183]. High levels of lupus activity are an additional risk but cases do exist where gallbladder vasculitis has occurred in quiescent disease
[185]. Unfortunately the diagnosis of acalculous cholecystitis typically occurs after surgical exploration and pathology evaluation. Conservative management with oral steroids may be successful in treating lupus-related inflammatory changes of the gallbladder if pre-operative suspicion is high and the process is identified early [186].

A strong association between primary biliary cirrhosis (PBC) and connective tissue diseases was documented by Culp who found $84 \%$ of 113 PBC patients had the associated presence of some other auto-immune illness (66\%) [187]. While strong associations have also been seen between Keratoconjunctivitis Sicca, CREST syndrome, Raynauds and $\mathrm{AIH}$, only scattered case reports exist throughout the literature associating PBC and SLE [127, 188, 189]. Patients within the case reports tend to develop signs and symptoms of lupus at variable intervals after the PBC diagnosis has been established [188, 190, 191]. Most are ANA and antimitochondrial antibody (AMA) positive although some studies have found the titers of both markers vary inversely with each other as clinical symptoms of lupus activity fluctuate [188-190]. However, antibody profiles may not always be useful in assisting either the diagnosis or prediction of risk for overlapping disease. ANA is present in patients with isolated PBC an estimated $33 \%$ of the time. The antibody is usually directed against a 200-KD polypeptide of the nuclear envelope with a peri-nuclear fluorescence, helping to distinguish it from the ANA seen more typically in SLE [192]. The presence of anti-mitochondrial antibodies in SLE patients has shown a limited occurrence (1\%) [191] but may help predict a course of disease. Li evaluated lupus patients with and without the anti-mitochondial antibody and found SLE patients with a positive AMA had an elevated risk of hepatic dysfunction with a positive correlation between AMA titers and liver enzyme levels [193]. Treatment should be directed toward the PBC and accomplished with the help of a gastroenterologist.

Primary sclerosing cholangitis (PSC) is also associated with SLE in rare case reports $[189,194]$. Auto-immune related biliary duct disease has also been seen in patients with clinical and serologic evidence of active SLE without the presence of the PBC-related anti-mitochondrial antibody [195].

\section{CONCLUSION}

In recent years there have been major advances in recognizing and understanding the presence of gastrointestinal manifestations of SLE. The frequency of GI manifestations related to SLE is likely more common than originally thought. Establishing a diagnosis often presents a major challenge to clinicians who must correctly interpret vague signs and symptoms that may represent the initial manifestation of disease, a secondary complication of existing disease or the side effect of an immune suppressing medicine. As in any disease, early recognition benefits the patient through treatment of not only the specific GI manifestation at hand, but also that of the generalized inflammation of SLE that may also damage other organ systems. Management strategies require an exquisitely detailed history and physical exam focusing on either activity of existing SLE if the diagnosis is known or risk factors and ACR criteria if the diagnosis is novel. Serologic markers of disease activity, antibody 
profiles, radiographic imaging and tissue samples through biopsy are among those tools that may aide in diagnosis. If the gastrointestinal manifestation is linked primarily to SLE, treatment often utilizes the traditional regimens aimed at controlling the systemic inflammation; if it is thought related to a medication adverse effect, a complication of immune system suppression or an associated condition such as Crohns, UC or PSC, treatment is altered accordingly. As our understanding of the pathophysiology of SLE grows, a better classification of these manifestations will develop and allow for better and more unique therapeutic regimens that will impact positively on morbidity and mortality. For now, understanding the potential presentations of SLE along the GI tract will be the greatest tool for treating these manifestations in the clinical setting.

\section{ABBREVIATION}

$$
\begin{aligned}
& \text { AGDS }=\text { Acute gastrointestinal distress syndrome } \\
& \text { ANA }=\text { Anti-nuclear antibody } \\
& \text { CIPO }=\text { Chronic intestinal pseudo obstruction } \\
& \text { DMARD }=\text { Disease modifying anti-rheumatic drug } \\
& \text { DsDNA }=\text { Anti-double stranded DNA antibody } \\
& \text { GERD }=\text { Gastro-esophageal reflux disease } \\
& \text { MCTD }=\text { Mixed connective tissue disease } \\
& \text { MIVOD }=\text { Mesenteric inflammatory veno-occlusive } \\
& \text { NSAID }=\text { Non-steroidal anti-inflammatory drug } \\
& \text { PA } \\
& \text { PLE }
\end{aligned}
$$

\section{REFERENCES}

[1] Tan EM, Cohen AS, Fries JF, et al. The 1982 revised criteria for the classification of systemic lupus erythematosus. Arthritis Rheum 1982; 25: 271-7.

[2] Hochberg MC. Updating the American College of Rheumatology revised criteria for the classification of systemic lupus erythematosus. Arthritis Rheum 1997; 40: 1725.

[3] Cohen AS, Canoso JJ. Criteria for the classification of systemic lupus erythematosus--status. Arthritis Rheum 1972; 15: 540-3.

[4] Vitali C, Doria A, Tincani A, et al. International survey on the management of patients with SLE. I. General data on the participating centers and the results of a questionnaire regarding mucocutaneous involvement. Clin Exp Rheumatol 1996; 14(Suppl 16): S1722.

[5] Al-Attai HM, Al Ahmed YH. Mucocutaneous disease in Arabs with systemic lupus erythematosus: clinical expression and relevance to autoantibodies. Lupus 1998; 7(8): 535-9.

[6] Urman JD, Lowenstein MB, Abeles M, et al. Oral mucosal ulceration in systemic lupus erythematosus. Arthritis Rheum 1978; 21(1): 58-61.

[7] Pistiner M, Wallace DJ, Nessim S, et al. Lupus erythematosus in the 1980s: a survey of 570 patients. Semin Arthritis Rheum 1991; 21(1): 55-64.
[8] Sultan SM, Ioannou Y, Isenberg DA. A review of gastrointestinal manifestations of systemic lupus erythematosus. Rheumatology (Oxford) 1999; 38(10): 917-32.

[9] Patel P, Werth V. Cutaneous lupus erythematosus: a review. Dermatol Clin 2002; 20(3): 373-85.

[10] Schiodt M. Oral discoid lupus erythematosus. III. A histopathologic study of sixty-six patients. Oral Surg Oral Med Oral Pathol 1984; 57(3): 281-93.

[11] Jonsson R, Heyden G, Westberg NG, et al. Oral mucosal lesions in systemic lupus erythematosus--a clinical, histopathological and immunopathological study. J Rheumatol 1984; 11(1): 38-42.

[12] Hallegua DS, Wallace CJ. Gastrointestinal and Hepatic Manifestations. In: Wallace DJ, Hahn BH, Eds. Dubois' Lupus Erythematosus: $6^{\text {th }}$ ed. Philadelphia: Lippincott Williams and Wilkins 2002; 843-57.

[13] Sanchez R, Jonsson R, Ahlfors E, et al. Oral lesions of lupus erythematosus patients in relation to other chronic inflammatory oral diseases: an immunologic study. Scand J Dent Res 1988; 96(6): 569-78.

[14] Karjalainen T, Tomich C. A histopathologic study of oral mucosal lupus erythematosus. Oral Surg Oral Med Oral Pathol 1989; 67(5): 547-54.

[15] Schiodt M. Oral discoid lupus erythematosus. II. Skin lesions and systemic lupus erythematosus in sixty-six patients with 6-year follow-up. Oral Surg Oral Med Oral Pathol 1984; 57(2): 177-80.

[16] Dayal NA, Isenberg DA. SLE/myositis overlap: are the manifestations of SLE different in overlap disease? Lupus 2002; 11(5): 293 8.

[17] Ramos-Casals M, Cuadrado MJ, Alba P, et al. Acute viral infections in patients with systemic lupus erythematosus: description of 23 cases and review of the literature. Medicine (Baltimore) 2008; 87: 311-8.

[18] Gutierrez F, Valenzuela JE, Ehresmann GR, et al. Esophageal dysfunction in patients with mixed connective tissue diseases and systemic lupus erythematosus. Dig Dis Sci 1982; 27(7): 592-7.

[19] Castrucci G, Alimandi L, Fichera A, et al. Changes in esophageal motility in patients with systemic lupus erythematosus: an esophago-manometric study. Minerva Dietol Gastroenterol 1990; 36(1): 3-7.

[20] Ramirez-Mata M, Reyes PA, Alarcon-Segovia D, et al. Esophageal motility in systemic lupus erythematosus. Am J Dig Dis 1974; 19(2): 132-6.

[21] Nadorra RL, Nakayato Y, Landing BH. Pathologic features of gastrointestinal tract lesions in childhood-onset systemic lupus erythematosus: study of 26 patients, with review of the literature. Pediatr Pathol 1987; 7(3): 245-59.

[22] Lapadula G, Muolo P, Semeraro F, et al. Esophageal motility disorders in the rheumatic diseases: a review of 150 patients. Clin Exp Rheumatol 1994; 12(5): 515-21.

[23] Peppercorn MA, Docken WP, Rosenberg S. Esophageal motor dysfunction in systemic lupus erythematosus. Two cases with unusual features. JAMA 1979; 242(17): 1895-6.

[24] Chua S, Dodd H, Saeed IT, et al. Dysphagia in a patient with lupus and review of the literature. Lupus 2002; 11(5): 322-4.

[25] Yu KH, Yang CH, Chu CC. Swallowing disturbance due to isolated vagus nerve involvement in systemic lupus erythematosus. Lupus 2007; 16: 746-9.

[26] Csendes A, Burdiles P. Scientific foundations for medical treatment based on modifying diet, lifestyle habits, and patient attitudes in chronic gastroesophageal reflux disease. Cir Esp 2007; 81(2): 64-9.

[27] Yeomans ND, Tulassay Z, Juhasz L, et al. A comparison of omeprazole with ranitidine for ulcers associated with nonsteroidal antiinflammatory drugs. Acid Suppression Trial: Ranitidine versus Omeprazole for NSAID-associated Ulcer Treatment (ASTRONAUT) Study Group. N Engl J Med 1998; 338(11): 719-26.

[28] Griffin MR, Smalley WE. Drugs and ulcers: clues about mucosal protection from epidemiologic studies. J Clin Gastroenterol 1995; 21(Suppl 1): S113-9.

[29] Pecora PG, Kaplan B. Corticosteroids and ulcers: is there an association? Ann Pharmacother 1996; 30(7-8): 870-2.

[30] Musaev SN, Novikova AV, Shershevskaia AI, et al. The morphometric and immunohistochemical characteristics of the gastric and duodenal mucosa in systemic lupus erythematosus. Biull Eksp Biol Med 1991; 111(2): 203-6.

[31] Junca J, Cuxart A, Olive A, et al. Anti-intrinsic factor antibodies in systemic lupus erythematosus. Lupus. 1993; 2(2): 111-4. 
[32] Archimandritis A, Tsirantonaki M, Tzivras M, et al. Watermelon stomach in a patient with vitiligo and systemic lupus erythematosus. Clin Exp Rheumatol 1996; 14(2): 227-8.

[33] Elinav E, Korem M, Ofran Y, et al. Hyperplastic gastropathy as a presenting manifestation of systemic lupus erythematosus. Lupus 2004; 13(1): 60-3.

[34] Mann SD, Debinski HS, Kamm MA. Clinical characteristics of chronic idiopathic intestinal pseudo-obstruction in adults. Gut 1997; 41(5): 675-81.

[35] Luman W, Chua KB, Cheong WK, et al. Gastrointestinal manifestations of systemic lupus erythematosus. Singapore Med J 2001; 42(8): 380-4.

[36] Mok MY, Wong RW, Lau CS. Intestinal pseudo-obstruction in systemic lupus erythematosus: an uncommon but important clinical manifestation. Lupus 2000; 9(1): 11-8.

[37] Pardos-Gea J, Ordi-Ros J, Selva A, et al. Chronic intestinal pseudoobstruction associated with biliary tract dilatation in a patient with systemic lupus erythematosus. Lupus 2005; 14(4): 328-30.

[38] Perlemuter G, Chaussade S, Wechsler B, et al. Chronic intestinal pseudo-obstruction in systemic lupus erythematosus. Gut 1998; 43(1): 117-22.

[39] Lee CK, Ahn MS, Lee EY, et al. Acute Abdominal Pain in SLE: focus on lupus enteritis (GI vasculitis). Ann Rheum Dis 2002; 61: 547-50.

[40] Kaneko Y, Hirakata M, Suwa A, et al. Systemic lupus erythematosus associated with recurrent lupus enteritis and peritonitis. Clin Rheumatol 2004; 23(4): 351-4.

[41] Kishimoto M, Nasir A, Mor A, Belmont HM. Acute gastrointestinal distress syndrome in patients with systemic lupus erythematosus. Lupus 2007; 16: 137-41.

[42] Sunkureddi PR, Luu N, Xiao SY, et al. Eosinophilic enteritis with systemic lupus erythematosus. South Med J 2005; 98(10): 1049-52.

[43] Takeno M, Ishigatsubo. Intestinal manifestations in systemic lupus erythematosus. Intern Med 2006; 45(2): 41-2.

[44] Takahashi H, Ohara M, Imai K. Collagen diseases with gastrointestinal manifestations. Nihon Rinsho Meneki Gakkai Kaishi 2004; 27(3): 145-55

[45] DuBois El, Tuffanelli DL. Clinical manifestations of systemic lupus erythematosus. Computer analysis of 520 cases. JAMA 1964; 190: 104-11.

[46] Font J, Bosch X, Ferrer J, et al. Systemic lupus erythematosus and ulcerative colitis. Lancet 1988; 1(8588): 770.

[47] Gunnarsson I, Kanerud L, Pettersson E, et al. Predisposing factors in sulphasalazine-induced systemic lupus erythematosus. $\mathrm{Br} \mathrm{J}$ Rheumatol 1997; 36(10): 1089-94.

[48] Stevens HP, Ostlere LS, Rustin MH. Systemic lupus erythematosus in association with ulcerative colitis: related autoimmune diseases. Br J Dermatol 1994; 130(3): 385-9.

[49] Alikhan M, Cummings OW, Rex D. Subtotal colectomy in a patient with collagenous colitis associated with colonic carcinoma and systemic lupus erythematosus. Am J Gastroenterol 1997; 92(7): 1213-5.

[50] Bayless TM, Giardiello FM, Lazenby A, et al. Collagenous colitis. Mayo Clin Proc 1987; 62(8): 740-1.

[51] Heckerling P, Urtubey A, Te J. Collagenous colitis and systemic lupus erythematosus. Ann Intern Med 1995; 122(1): 71-2.

[52] Perednia DA, Curosh NA. Lupus-associated protein-losing enteropathy. Arch Intern Med 1990; 150(9): 1806-10.

[53] Mok CC, Ying KY, Mak A, et al. Outcome of protein-losing gastroenteropathy in systemic lupus erythematosus treated with prednisolone and azathioprine. Rheumatology (Oxford) 2006; 45(4): 425-9.

[54] Zheng WJ, Tian XP, Li L, et al. Protein-loosing enteropathy in systemic luous erythematosus: analysis of the clinical features of fifteen patients. J Clin Rheumatol 2007; 13: 313-6.

[55] Oh DC, Ng TM, Ho J, et al. Systemic lupus erythematosus with concurrent protein-losing enteropathy and primary sclerosing cholangitis: a unique association. Lupus 2006; 15(2): 102-4.

[56] Meulders Q, Michel C, Marteau P, et al. Association of chronic interstitial cystitis, protein-losing enteropathy and paralytic ileus with seronegative systemic lupus erythematosus: case report and review of the literature. Clin Nephrol 1992; 37(5): 239-44.

[57] Sunheimer RL, Finck C, Mortazavi S, et al. Primary lupusassociated protein-losing enteropathy. Ann Clin Lab Sci 1994; 24(3): 239-42.
[58] Edmunds SE, Ganju V, Beveridge BR, et al. Protein-losing enteropathy in systemic lupus erythematosus. Aust N Z J Med 1988; 18(7): 868-71.

[59] Benner KG, Montanaro A. Protein-losing enteropathy in systemic lupus erythematosus. Diagnosis and monitoring immunosuppressive therapy by alpha-1-antitrypsin clearance in stool. Dig Dis Sci 1989; 34(1): 132-5.

[60] Molina JF, Brown RF, Gedalia A, et al. Protein losing enteropathy as the initial manifestation of childhood systemic lupus erythematosus. J Rheumatol 1996; 23(7): 1269-71.

[61] Viallard JF, Fach J, Mercie P, et al. Exudative enteropathy in disseminated lupus erythematosus. Report of 3 cases and review of the literature. Ann Med Intern (Paris) 1998; 149(8): 485-91.

[62] Hizawa K, Iida M, Aoyagi K, et al. Double-contrast radiographic assessment of lupus-associated enteropathy. Clin Radiol 1998; 53(11): 825-9.

[63] Werner de Castro GR, Appenzeller S, Bertolo MB, et al. Proteinlosing enteropathy associated with systemic lupus erythematosus: response to cyclophosphamide. Rheumatol Int 2005; 25(2): 135-8.

[64] Weisman MH, McDanald EC, Wilson CB. Studies of the pathogenesis of interstitial cystitis, obstructive uropathy, and intestinal malabsorption in a patient with systemic lupus erythematosus. Am J Med 1981; 70(4): 875-81.

[65] Mader R, Adawi M, Schonfeld S. Malabsorption in systemic lupus erythematosus. Clin Exp Rheumatol 1997; 15(6): 659-61.

[66] Mirza N, Bonilla E, Phillips PE. Celiac disease in a patient with systemic lupus erythematosus: a case report and review of literature. Clin Rheumatol 2007; 26(5): 827-8.

[67] Rustgi AK, Peppercorn MA. Gluten-sensitive enteropathy and systemic lupus erythematosus. Arch Intern Med 1988; 148(7): $1583-4$.

[68] Davies MG, Marks R, Waddington E. Simultaneous systemic lupus erythematosus and dermatitis herpetiformis. Arch Dermatol 1976; 112(9): 1292-4.

[69] Thomas Jr 3rd, Su WP. Concurrence of lupus erythematosus and dermatitis herpetiformis. A report of nine cases. Arch Dermatol 1983; 119(9): 740-5.

[70] Grimbacher B, Huber M, von Kempis J, et al. Successful treatment of gastrointestinal vasculitis due to systemic lupus erythematosus with intravenous pulse cyclophosphamide: a clinical case report and review of the literature. Br J Rheumatol 1998; 37(9): 1023-8.

[71] Chou KT, Lee YC, Chen CW, et al. Lupus erythematosus (LE) cells in ascites: initial diagnosis of systemic lupus erythematosus by cytological examination: a case report. Clin Rheumatol 2007; 26(11): 1931-3.

[72] Chou KT, Lee YC, Chen CW, et al. Lupus erythematosus (LE) cells in ascites: initial diagnosis of systemic lupus erythematosus by cytological examination: a case report. Clin Rheumatol 2007; 26: 1931-3.

[73] Ishiguro N, Tomino Y, Fujito K, et al. A case of massive ascites due to lupus peritonitis with a dramatic response to steroid pulse therapy. Jpn J Med 1989; 28(5): 608-11.

[74] Low VH, Robins PD, Sweeney DJ. Systemic lupus erythematosus serositis. Australas Radiol 1995; 39(3): 300-2.

[75] Kaklamanis P, Vayopoulos G, Stamatelos G, et al. Chronic lupus peritonitis with ascites. Ann Rheum Dis 1991; 50(3): 176-7.

[76] Provenzano G, Rinaldi F, Le Moli S, et al. Chronic lupus peritonitis responsive to treatment with cyclophosphamide. Br J Rheumatol 1993; 32(12): 1116.

[77] Idequchi H, Misumi M, Inoue Y, et al. Two cases of acute lupus peritonitis. Ryumachi 2000; 40(6): 910-6.

[78] Breuer GS, Baer A, Dahan D, et al. Lupus-associated pancreatitis. Autoimmun Rev 2006; 5(5): 314-8.

[79] Derk CT, DeHoratius RJ. Systemic lupus erythematosus and acute pancreatitis: a case series. Clin Rheumatol 2004; 23(2): 147-51.

[80] Duncan HV, Achara G. A rare initial manifestation of systemic lupus erythematosus--acute pancreatitis: case report and review of the literature. J Am Board Fam Pract 2003; 16(4): 334-8.

[81] Duval A, Lamare L, Jian R, et al. Pancreatitis with hepatitis revealing a systemic lupus erythempatosus. Gastroenterol Clin Biol 2008; 32: 417-20.

[82] Richer O, Ulinski T, Lemelle I, et al. Abdominal manifestations in childhood onset systemic lupus erythematosus. Ann Rheum Dis 2007; 66: 174-8. 
[83] Wang F, Wang NS, Zhao BH, et al. Acute pancreatitis as an initial symptom of systemic lupus erythematosus: a case report and review of the literature. World J Gastroenterol 2005; 11(30): 4766-8.

[84] Frank B, Gottlieb K. Amylase normal, lipase elevated: is it pancreatitis? A case series and review of the literature. Am J Gastroenterol 1999; 94(2): 463-9.

[85] Nesher G, Breuer GS, Temprano K, et al. Lupus-associated pancreatitis. Semin Arthritis Rheum 2006; 35(4): 260-7.

[86] Ranson JH. Diagnostic standards for acute pancreatitis. World J Surg 1997; 21(2): 136-42.

[87] Hasselbacher P, Myers AR, Passero AR. Serum amylase and macroamylase in patients with systemic lupus erythematosus. $\mathrm{Br} \mathrm{J}$ Rheumatol 1988; 27(3): 198-201.

[88] Petri M. Pancreatitis in systemic lupus erythematosus: still in search of a mechanism. J Rheumatol 1992; 19(7): 1014-6.

[89] Reynolds JC, Inman RD, Kimberly RP, et al. Acute pancreatitis in systemic lupus erythematosus: report of twenty cases and a review of the literature. Medicine (Baltimore) 1982; 61(1): 25-32.

[90] Takasaki M, Yorimitsu Y, Takahashi I, et al. Systemic lupus erythematosus presenting with drug-unrelated acute pancreatitis as an initial manifestation. Am J Gastroenterol 1995; 90(7): 1172-3.

[91] Penalva JC, Martinez J, Pascual E, et al. Chronic pancreatitis associated with systemic lupus erythematosus in a young girl. Pancreas 2003; 27(3): 275-7.

[92] Riemenschneider TA, Wilson JF, Venier RL. Glucocorticoidinduced pancreatitis in children. Pediatrics 1968; 41(2): 428-37.

[93] Oppenheimer EH, Boitnott JK. Pancreatitis in children following adrenal cortico-steroid therapy. Bull Johns Hopkins Hosp 1960; 107: 297-306.

[94] Carone FA, Liebow AA. Acute pancreatic lesions in patients treated with ACTH and adrenal corticoids. N Engl J Med 1957; 257(15): 690-7.

[95] Bruijn JA, van Albada-Kuipers GA, Smit VT, et al. Acute pancreatitis in systemic lupus erythematosus. Scand J Rheumatol 1986; 15(4): 363-7.

[96] Saab S, Coor MP, Weisman MH. Corticosteroids and systemic lupus erythematosus pancreatitis: a case series. J Rheumatol 1998; 25(4): 801-6.

[97] Watts RA, Eisenberg DA. Pancreatic disease in the autoimmune rheumatic disorders. Semin Arthritis Rheum 1989; 19(3): 158-65.

[98] Borum M, Steinberg W, Steer M, et al. Chronic pancreatitis: a complication of systemic lupus erythematosus. Gastroenterology 1993; 104(2): 613-5.

[99] Hortas C, de Las Heras G, Lopez-Arias MJ, et al. Chronic calcifying pancreatitis in rheumatic diseases. Ann Rheum Dis 1995; 54(1): 77-8.

[100] Vitali C, Bencivelli W, Isenberg DA, et al. Disease activity in systemic lupus erythematosus: report of the Consensus Study Group of the European Workshop for Rheumatology Research. I. A descriptive analysis of 704 European lupus patients. European Consensus Study Group for Disease Activity in SLE. Clin Exp Rheumatol 1992; 10(5): 527-39.

[101] Drenkard C, Villa AR, Reyes E, et al. Vasculitis in systemic lupus erythematosus. Lupus 1997; 6(3): 235-42.

[102] Medina F, Ayala A, Jara LJ, et al. Acute Abdomen in SLE: The Importance of Early Laparotomy. Am J Med 1997; 103(2): 100105 .

[103] Hiraishi H, Konishi T, Ota S, et al. Massive gastrointestinal hemorrhage in systemic lupus erythematosus: successful treatment with corticosteroid pulse therapy. Am J Gastroenterol 1999; 94(11): 3349-53.

[104] Buck AC, Serebro LH, Quinet RJ. Subacute abdominal pain requiring hospitalization in a systemic lupus erythematosus patient: a retrospective analysis and review of the literature. Lupus 2001; 10(7): 491-5.

[105] Rothfield N, Sontheimer RD, Bernstein M. Lupus Erythematosus: Systemic and Cutaneous manifestations. Clin Dermatol 2006; 24 : 348-62.

[106] Byun JY, Ha HK, Yu SY, et al. CT features of systemic lupus erythematosus in patients with acute abdominal pain: emphasis on ischemic bowel disease. Radiology 1999; 211(1): 203-9.

[107] Taourel P, Pradel J, Fabre JM, et al. Role of CT in the acute nontraumatic abdomen. Semin Ultrasound CT MR. 1995; 16(2): 151-64.
[108] Taourel PG, Deneuville M, Pradel JA, et al. Acute mesenteric ischemia: diagnosis with contrast-enhanced CT. Radiology 1996; 199(3): 632-6.

[109] Ko SF, Lee TY, Cheng TT, et al. CT findings at lupus mesenteric vasculitis. Acta Radiol 1997; 38(1): 115-20.

[110] Serrano-Lopez MC, Yebra-Bango M, Lopez Bonet E, et al. Acute pancreatitis and systemic lupus erythematosus: necropsy of a case and review of the pancreatic vascular lesions. Am J Gastroenterol 1991; 86(6): 764-7.

[111] Kistin MG, Kaplan MM, Harrington JT. Diffuse ischemic colitis associated with systemic lupus erythematosus--response to subtotal colectomy. Gastroenterology 1978; 75(6): 1147-51.

[112] Amit G, Stalnikowicz R, Ostrovsky Y, et al. Rectal ulcers: a rare gastrointestinal manifestation of systemic lupus erythematosus. J Clin Gastroenterol 1999; 29(2): 200-2.

[113] Teramoto J, Takahaski Y, Katsuki S, et al. Systemic lupus erythematosus with a giant rectal ulcer and perforation. Intern Med 1999; 38(8): 643-9.

[114] Reissman P, Weiss EG, Teoh TA, et al. Gangrenous ischemic colitis of the rectum: a rare complication of systemic lupus erythematosus. Am J Gastroenterol 1994; 89(12): 2234-6.

[115] Yuasa S, Suwa A, Hirakata M, et al. A case of systemic lupus erythematosus presenting with rectal ulcers as the initial clinical manifestation of disease. Clin Exp Rheumatol 2002; 20(3): 407-10.

[116] Zizic TM, Classen JN, Stevens MB. Acute abdominal complications of systemic lupus erythematosus and polyarteritis nodosa. Am J Med 1982; 73(4): 525-31.

[117] Train JS, Hertz I, Cohen BA, et al. Lupus vasculitis: Reversal of radiographic findings after steroid therapy. Am J Gastroenterol 1981; 76: 460.

[118] Ko SF, Hsien MJ, Ng SH, et al. Superior mesenteric artery aneurysm in systemic lupus erythematosus. Clin Imaging 1997; 21(1): 13-6.

[119] Bando H, Kobayashi S, Matsumoto T, et al. Acute acalculous cholecystitis induced by mesenteric inflammatory veno-occlusive disease (MIVOD) in systemic lupus erythematosus. Clin Rheumatol 2003; 22(6): 447-9.

[120] Gul A, Inanc M, Ocal L, et al. Primary antiphospholipid syndrome associated with mesenteric inflammatory veno-occlusive disease. Clin Rheumatol 1996; 15(2): 207-10.

[121] Flaherty MJ, Lie JT, Haggitt RC. Mesenteric inflammatory venoocclusive disease. A seldom recognized cause of intestinal ischemia. Am J Surg Pathol 1994; 18(8): 779-84.

[122] Lie JT. Mesenteric inflammatory veno-occlusive disease (MIVOD): an emerging and unsuspected cause of digestive tract ischemia. VASA 1997; 26(2): 91-6.

[123] Hu JC, Forshaw MJ, Thebe P, et al. Mesenteric inflammatory veno-occlusive disease as a cause of acute abdomen: report of five cases. Surg Today 2005; 35(11): 961-4.

[124] Hoffman BI, Katz WA. The gastrointestinal manifestations of systemic lupus erythematosus: a review of the literature. Semin Arthritis Rheum 1980; 9(4): 237-47.

[125] Kamiuchi K, Sano H, Hashiramoto A, et al. A case of systemic lupus erythematosus complicated with marked intestinal edema and paralytic ileus. Nihon Rinsho Meneki Gakkai Kaishi 1998; 21(1): 48-56.

[126] Waite L, Morrison E. Severe gastrointestinal involvement in systemic lupus erythematosus treated with rituximab and cyclophosphamide (B-cell depletion therapy). Lupus 2007; 16: 841-2.

[127] Hallegua DS, Wallace DJ. Gastrointestinal manifestations of systemic lupus erythematosus. Curr Opin Rheumatol 2000; 12(5): 379-85.

[128] Al-Hakeem MS, McMillen MA. Evaluation of abdominal pain in systemic lupus erythematosus. Am J Surg 1998; 176(3): 291-4.

[129] Lian TY, Edwards CJ, Chan SP, et al. Reversible acute gastrointestinal syndrome associated with active systemic lupus erythematosus in patients admitted to hospital. Lupus 2003; 12(8): 612-6.

[130] Phongkitkarun S, Boonnumsirikij M, Jatchavala J, et al. Abdominal manifestation and complications in systemic lupus erythematosus: emphasis on CT findings. J Med Assoc Thai 2007; 90: 2112-20.

[131] Gore RM, Marn CS, Ujiki GT, et al. Ischemic colitis associated with systemic lupus erythematosus. Dis Colon Rectum 1983; 26(7): 449-51.

[132] Koh ET, Boey ML, Feng PH. Acute surgical abdomen in systemic lupus erythematosus--an analysis of 10 cases. Ann Acad Med Singapore 1992; 21(6): 833-7. 
[133] Yamasaki S, Origuchi T, Nakata K, et al. Autoimmune hepatitis in a patient with systemic lupus erythematosus: a case report. Mod Rheumatol 2004; 14(2): 169-73.

[134] Matsumoto T, Kobayashi S, Shimizu H, et al. The liver in collagen diseases: pathologic study of 160 cases with particular reference to hepatic arteritis, primary biliary cirrhosis, autoimmune hepatitis and nodular regenerative hyperplasia of the liver. Liver 2000; 20(5): 366-73.

[135] Abraham S, Begum S, Isenberg D. Hepatic manifestations of autoimmune rheumatic diseases. Ann Rheum Dis 2004; 63(2): 1239.

[136] Caramaschi P, Biasi D, Botto M, et al. Liver involvement in systemic lupus erythematosus. Recenti Prog Med 1993; 84(10): 673-8.

[137] van Hoek B. The spectrum of liver disease in systemic lupus erythematosus. Neth J Med 1996; 48(6): 244-53.

[138] Suzuki A, Sekiyama N, Koito N, et al. Liver disease in systemic lupus erythematosus. Nihon Rinsho Meneki Gakkai Kaishi 1995; 18(1): 53-9.

[139] Runyon BA, LaBrecque DR, Anuras S. The spectrum of liver disease in systemic lupus erythematosus. Report of 33 histologicallyproved cases and review of the literature. Am J Med 1980; 69(2): 187-94.

[140] Miller MH, Urowitz MB, Gladman DD, et al. The liver in systemic lupus erythematosus. Q J Med 1984; 53(211): 401-9.

[141] Mok CC. Investigations and management of gastrointestinal and hepatic manifestations of systemic lupus erythematosus. Best Pract Res Clin Rheumatol 2005; 19(5): 741-66.

[142] Gibson T, Myers AR. Subclinical liver disease in systemic lupus erythematosus. J Rheumatol 1981; 8(5): 752-9.

[143] Hulsey M, Goldstein R, Scully L, et al. Anti-ribosomal P antibodies in systemic lupus erythematosus: a case-control study correlating hepatic and renal disease. Clin Immunol Immunopathol 1995; 74(3): 252-6.

[144] Arnett FC, Reichlin M. Lupus hepatitis: an under-recognized disease feature associated with autoantibodies to ribosomal P. Am J Med 1995; 99(5): 465-72.

[145] Matsumoto T, Yoshimine T, Shimouchi K, et al. The liver in systemic lupus erythematosus: pathologic analysis of 52 cases and review of Japanese Autopsy Registry Data. Hum Pathol 1992; 23(10): 1151-8.

[146] Wood JR, Czaja AJ, Beaver SJ, et al. Frequency and significance of antibody to double-stranded DNA in chronic active hepatitis. Hepatology 1986; 6(5): 976-80.

[147] Hall S, Czaja AJ, Kaufman DK, et al. How lupoid is lupoid hepatitis? J Rheumatol 1986; 13(1): 95-8.

[148] Cowling DC, Mackay IR, Taft LI. Lupoid hepatitis. Lancet 1956; 271(6957): 1323-6.

[149] Alvarez F, Berg PA, Bianchi FB, et al. International Autoimmune Hepatitis Group Report: review of criteria for diagnosis of autoimmune hepatitis. J Hepatol 1999; 31(5): 929-38.

[150] Kooy A, deHeide LJ, Engelkens HJ, et al. How to diagnose autoimmune hepatitis in systemic lupus erythematosus? Hepatology 1996; 23(4): 936-8.

[151] Czaja AJ, Freese DK. Diagnosis and treatment of autoimmune hepatitis. Hepatology 2002; 36(2): 479-97.

[152] Tojo J, Ohira H, Abe K. Autoimmune hepatitis accompanied by systemic lupus erythematosus. Intern Med 2004; 43(3): 258-62.

[153] Iwai M, Harada Y, Ishii M, et al. Autoimmune hepatitis in a patient with systemic lupus erythematosus. Clin Rheumatol 2003; 22(3): 234-6.

[154] Yoon JU, Park SH, Kim EJ, et al. Two cases of autoimmnune hepatitis associated with systemic lupus erythematosus. Taehan Kan Hakhoe Chi 2003; 9(3): 231-5.

[155] Omagari K, Masuda J, Kato Y, et al. Re-analysis of clinical features of 89 patients with autoimmune hepatitis using the revised scoring system proposed by the International Autoimmune Hepatitis Group. Intern Med 2000; 39(12): 1008-12.

[156] Czaja AJ. Treatment of autoimmune hepatitis. Semin Liver Dis 2002; 22(4): 365-78.

[157] Czaja AJ. Emerging treatments for autoimmune hepatitis. Curr Drug Targets Inflamm Allergy 2002; 1(4): 317-26.

[158] Horita T, Tsutsumi A, Takeda T, et al. Significance of magnetic resonance imaging in the diagnosis of nodular regenerative hyperplasia of the liver complicated with systemic lupus erythematosus: a case report and review of the literature. Lupus 2002; 11(3): 1936.
[159] Klein R, Goller S, Bianchi L. Nodular regenerative hyperplasia (NRH) of the liver--a manifestation of 'organ-specific antiphospholipid syndrome'? Immunobiology 2003; 207(1): 51-7.

[160] Angulo JM, Sigal LH, Espinoza LR. Coexistent minocyclineinduced systemic lupus erythematosus and autoimmune hepatitis. Semin Arthritis Rheum 1998; 28(3): 187-92.

[161] Elkayam O, Yaron M, Caspi D. Minocycline-induced autoimmune syndromes: an overview. Semin Arthritis Rheum 1999; 28(6): 3927 .

[162] Graziadei IW, Obermoser GE, Sepp NT, et al. Drug-induced lupuslike syndrome associated with severe autoimmune hepatitis. Lupus 2003; 12(5): 409-12.

[163] Asherson RA, Thompson RP, MacLachlan N, et al. Budd Chiari syndrome, visceral arterial occlusions, recurrent fetal loss and the "lupus anticoagulant" in systemic lupus erythematosus. J Rheumatol 1989; 16(2): 219-24.

[164] Atsumi T, Sagawa A, Jodo S, et al. Severe hepatic involvement without inflammatory changes in systemic lupus erythematosus: report of two cases and review of the literature. Lupus 1995; 4(3): 225-8.

[165] Suzuki T, Tsuchiya N, Ito K. Multiple cavernous hemangiomas of the liver in patients with systemic lupus erythematosus. J Rheumatol 1997; 24(4): 810-1.

[166] Garcia-Tobaruela A, Gil A, Lavilla P, et al. Hepatic amyloidosis associated with systemic lupus erythematosus. Lupus 1995; 4(1): 75-7.

[167] Kim TY, Lee SH, Kim TJ, et al. A case of fulminant hepatic failure in Wilson's disease combined with systemic lupus erythematosus. Taehan Kan Hakhoe Chi 2002; 8(1): 100-4.

[168] Abu-Shakra M, El-Sana S, Margalith M, et al. Hepatitis B and C viruses serology in patients with SLE. Lupus 1997; 6(6): 543-4.

[169] Chung HH, Fock KM, Chew CN, et al. Hepatitis B virus infection in patients with systemic lupus erythematosus. Singapore Med J 1993; 34(4): 325-6.

[170] Lu CL, Tsai ST, Chan CY, et al. Hepatitis B infection and changes in interferon-alpha and -gamma production in patients with systemic lupus erythematosus in Taiwan. J Gastroenterol Hepatol 1997; 12(4): 272-6.

[171] Lai KN, Lai FM, Lo S, et al. Is there a pathogenetic role of hepatitis B virus in lupus nephritis? Arch Pathol Lab Med 1987; 111(2): 185-8.

[172] Mac-Moune, Lai KN, Lee JC, et al. Hepatitis B virus-related glomerulopathy in patients with systemic lupus erythematosus. Am J Clin Pathol 1987; 88(4): 412-20.

[173] Hanslik T, Vaillant JN, Jubault V, et al. Systemic lupus erythematosus and risk of hepatitis B vaccination: from level of evidence to prescription. Rev Med Interne 2000; 21(9): 785-90.

[174] Karakoc Y, Dilek K, Gullulu M, et al. Prevalence of hepatitis C virus antibody in patients with systemic lupus erythematosus. Ann Rheum Dis 1997; 56(9): 570-1.

[175] Ramos-Casals M, Font J, Garcia-Carrasco M, et al. Hepatitis C virus infection mimicking systemic lupus erythematosus: study of hepatitis $\mathrm{C}$ virus infection in a series of 134 Spanish patients with systemic lupus erythematosus. Arthritis Rheum 2000; 43(12): 2801-6.

[176] Ahmed MM, Berney SM, Wolf RE, et al. Prevalence of active hepatitis $\mathrm{C}$ virus infection in patients with systemic lupus erythematosus. Am J Med Sci 2006; 331(5): 252-6.

[177] Kowdley KV, Subler DE, Scheffel J, et al. Hepatitis C virus antibodies in systemic lupus erythematosus. J Clin Gastroenterol 1997; 25(2): 437-9.

[178] Cacoub P, Poynard T, Ghillani P, et al. Extrahepatic manifestations of chronic hepatitis C. MULTIVIRC Group. Multidepartment Virus C. Arthritis Rheum 1999; 42(10): 2204-12.

[179] Feng H, Zhang GY, Xie HF, et al. Hepatitis C virus infection combined with systemic lupus erythematosus. Zhong Nan Da Xue Xue Bao Yi Xue Ban 2006; 31(6): 891-3.

[180] Perlemuter G, Cacoub P, Sbai A, et al. Hepatitis C virus infection in systemic lupus erythematosus: a case-control study. J Rheumatol 2003; 30(7): 1473-8.

[181] Wilson LE, Widman D, Dikman SH, et al. Autoimmune disease complicating antiviral therapy for hepatitis $\mathrm{C}$ virus infection. Semin Arthritis Rheum 2002; 32(3): 163-73.

[182] Martinez D, Lowe R. Case report: systemic lupus erythematosus (SLE) serositis mimicking acute cholecystitis. Clin Radiol 1991; 44(6): 434-5. 
[183] Dessailloud R, Papo T, Vaneecloo S, et al. Acalculous Ischemic Gallbladder Necrosis in the Catastrophic Antiphospholipid Syndrome. Arthritis and Rheumatism 1998; 41(7): 1318-1320.

[184] Swanepoul CR, Floyd A, Allison H, et al. Acute acalculous cholecystitis complicating systemic lupus erythematosus: case report and review. Br Med J (Clin Res Ed) 1983; 286(6361): 251-2.

[185] Newbold KM, Allum WH, Downing R, et al. Vasculitis of the gall bladder in rheumatoid arthritis and systemic lupus erythematosus. Clin Rheumatol 1987; 6(2): 287-9.

[186] Kamimura T, Mimori A, Takeda A, et al. Acute acalculous cholecystitis in systemic lupus erythematosus: a case report and review of the literature. Lupus 1998; 7(5): 361-3.

[187] Culp KS, Fleming CR, Duffy J, et al. Autoimmune associations in primary biliary cirrhosis. Mayo Clin Proc 1982; 57(6): 365-70.

[188] Schifter T, Lewinski UH. Primary biliary cirrhosis and systemic lupus erythematosus. A rare association. Clin Exp Rheumatol 1997; 15(3): 313-4.

[189] Kadokawa Y, Omagari K, Matsuo I, et al. Primary sclerosing cholangitis associated with lupus nephritis: a rare association. Dig Dis Sci 2003; 48(5): 911-4.

[190] Hall S, Axelson PH, Larson DE, et al. Systemic lupus erythematosus developing in patients with primary biliary cirrhosis. Ann Intern Med 1984; 100(3): 388-9.
[191] Islam S, Riordan JW, McDonald JA. Case report: a rare association of primary biliary cirrhosis and systemic lupus erythematosus and review of the literature. J Gastroenterol Hepatol 1999; 14(5): 4315.

[192] Lassoued K, Brenard R, Degos F, et al. Antinuclear antibodies directed to a 200-kilodalton polypeptide of the nuclear envelope in primary biliary cirrhosis. A clinical and immunological study of a series of 150 patients with primary biliary cirrhosis. Gastroenterology 1990; 99(1): 181-6.

[193] Li CH, Xu PS, Wang CY, et al. Increased serum aminotransferases associated with anti-mitochondrial antibodies in systemic lupus erythematosus patients with autoimmune liver disease. Clin Chim Acta 2006; 365(1-2): 135-42.

[194] Audan A, Bruley Des Varannes S, Georgelin T, et al. Primary sclerosing cholangitis and systemic lupus erythematosus. Gastroenterol Clin Biol 1995; 19(1): 123-6.

[195] Heyman SN, Spectre G, Aamar S, et al. Autoimmune cholangiopathy associated with systemic lupus erythematosus. Liver 2002; 22(2): 102-6.

(C) Schulz and Derk; Licensee Bentham Open.

This is an open access article licensed under the terms of the Creative Commons Attribution Non-Commercial License (http: //creativecommons. org/licenses/ by-nc/3. 0/) which permits unrestricted, non-commercial use, distribution and reproduction in any medium, provided the work is properly cited. 